\title{
Reconsidering the evolution of brain, cognition, and behavior in birds and mammals
}

\section{Romain Willemet*}

Unaffiliated, Toulouse, France

\section{Edited by:}

Onur Gunturkun, Ruhr-University

Bochum, Germany

Reviewed by:

Jennifer Vonk, Oakland University, USA

Mathieu Lihoreau, The University of Sydney, Australia

Pavel Nemec, Charles University in

Prague, Czech Republic

*Correspondence:

Romain Willemet, Unaffiliated,

Toulouse, France

e-mail:r.willemet@gmx.com
Despite decades of research, some of the most basic issues concerning the extraordinarily complex brains and behavior of birds and mammals, such as the factors responsible for the diversity of brain size and composition, are still unclear. This is partly due to a number of conceptual and methodological issues. Determining species and group differences in brain composition requires accounting for the presence of taxon-cerebrotypes and the use of precise statistical methods. The role of allometry in determining brain variables should be revised. In particular, bird and mammalian brains appear to have evolved in response to a variety of selective pressures influencing both brain size and composition. "Brain" and "cognition" are indeed meta-variables, made up of the variables that are ecologically relevant and evolutionarily selected. External indicators of species differences in cognition and behavior are limited by the complexity of these differences. Indeed, behavioral differences between species and individuals are caused by cognitive and affective components. Although intra-species variability forms the basis of species evolution, some of the mechanisms underlying individual differences in brain and behavior appear to differ from those between species. While many issues have persisted over the years because of a lack of appropriate data or methods to test them; several fallacies, particularly those related to the human brain, reflect scientists' preconceptions. The theoretical framework on the evolution of brain, cognition, and behavior in birds and mammals should be reconsidered with these biases in mind.

Keywords: allometry, behavior, brain evolution, cerebrotypes, cognition, general intelligence, mentality, personality

\section{INTRODUCTION}

Despite decades of research, some of the most basic issues related to the evolution of brain, cognition, and behavior are still unclear. In particular, in birds and mammals, in which most research has been conducted, there are no satisfactory answers to the following questions: Which factors control species differences in brain size and composition and what is, if any, the role of body size? How do brain size and composition influence species behavior? What is the nature of species differences in cognition and behavior? As a matter of fact, the increasing number of hypotheses being proposed on evolutionary neuroscience and comparative cognition is at odds with the paucity of theoretical background. For example, there is a widespread belief that "although absolute brain size may partially explain species differences in intelligence, the fact that elephant and whale brains are several times larger than human brains gives us pause and suggests the need to control for body size" (Rilling, 2006). Yet, is it possible to compare species' brains irrespective of their taxa? Is it justified to consider body size as the main factor controlling brain size? Finally, should the human brain be taken as the reference brain when considering cognitive abilities? As discussed in this paper, the answers to these questions are negative.

More generally, there is a need for reconsidering some of the methodological and conceptual bases of comparative neuroscience. Examining the literature on birds and mammals, the present paper exposes definitive reasons for abandoning wholeclass analyses in comparative studies and highlights the importance of a detailed taxon-cerebrotype approach in brain evolution studies. Possible factors underlying the changes in brain size and composition inside a taxon-cerebrotype are presented, as well as potential factors associated with variation in relative brain size. These results are then summarized in a methodological section on measuring cognitive abilities between species and in a section about species variations in cognition and behavior. The final section discusses the significance of intra-species scaling in the evolution of brain and behavior.

\section{COMPARATIVE BRAIN STUDIES IN BIRDS AND MAMMALS}

In a sample of species ranging from bacteria and viruses to whales and sequoia, there is a fairly strong relationship between species size and generation time or population density (Harvey and Pagel, 1991, 3-4). Yet, because reproduction mechanisms as well as the mechanisms underlying population density differ between the taxonomic groups included in the sample, comparative analyses on the factors underlying such relationships are inappropriate at this phylogenetic level. This difficulty has generally been overlooked in evolutionary neuroscience, leading to some misleading concepts to be accepted and continuously reported. The encephalization quotient (EQ) approach developed by Jerison (1973) is an example of this concern. Basically, because brain 
size appears to increase regularly with body size by a power law in mammals, Jerison has suggested the possibility of calculating the expected brain mass of any species from its body mass and relating it to the processing capacity by the mean of the EQ (a measure of observed brain size relative to the expected brain size predicted by the brain/body power law). As betrayed by its frequency in literature, the very principle of the EQ method has been widely accepted. Yet, two major flaws, independently fatal for the EQ approach, are presented below (see also Herculano-Houzel, 2011a).

\section{BRAIN/BODY SCALING DIFFERENCES}

The minimal assumption for the EQ method to be valid is a universal exponent describing the relationship between brain and body size among mammals. Yet, such an exponent is theoretically implausible and not supported by empirical results (Worthy and Hickie, 1986; Harvey and Krebs, 1990). Thus, there is no "expected brain size" for any mammalian species because brain/body allometry is specific to each taxon. Besides, this suggests that the extensive debate on the value and significance of a hypothetical mammalian exponent [see review by Harvey and Krebs (1990)] is groundless. Such taxa-specific brain/body allometries, also present in birds (Mlikovsky, 1989; Nealen and Ricklefs, 2001), are widely acknowledged, but their effects largely underestimated (see also Deacon, 1990a). Yet, this causes a systematic bias in comparative analyses, visible for example when regressing brain and body size from simian and insectivore species [Figure 1, data from Stephan et al. (1981)]. All statistical analyses in this paper have been performed using $\mathrm{R}$ software ( $\mathrm{R}$ Development Core Team, 2011).

\section{TAXON-CEREBROTYPES}

Studies using the EQ assume that brain size is an estimate of processing capacity (Jerison, 1985). Such a hypothesis would require that mammalian brains are size variations of the same model; an issue tackled by the debate on whether the evolution of mammalian brain structures has been limited by some developmental constraints ("concerted evolution," Finlay and Darlington, 1995; Finlay et al., 2001), or whether the size of brain structures could vary independently between species ("mosaic evolution", Barton and Harvey, 2000). In fact, it is possible to define groups of brains that have evolved under a bauplan that differs from those of other taxa at most anatomical levels ("taxon-cerebrotypes" Willemet, 2012 after Clark et al., 2001). Such diversity, despite the presence of developmental [review in Charvet and Striedter (2011)] and functional (Kaas, 2000) constraints definitely undermines the notion of a "universal scaling law" (Jacobs, 2012) in the evolution of the mammalian brain structures (Willemet,

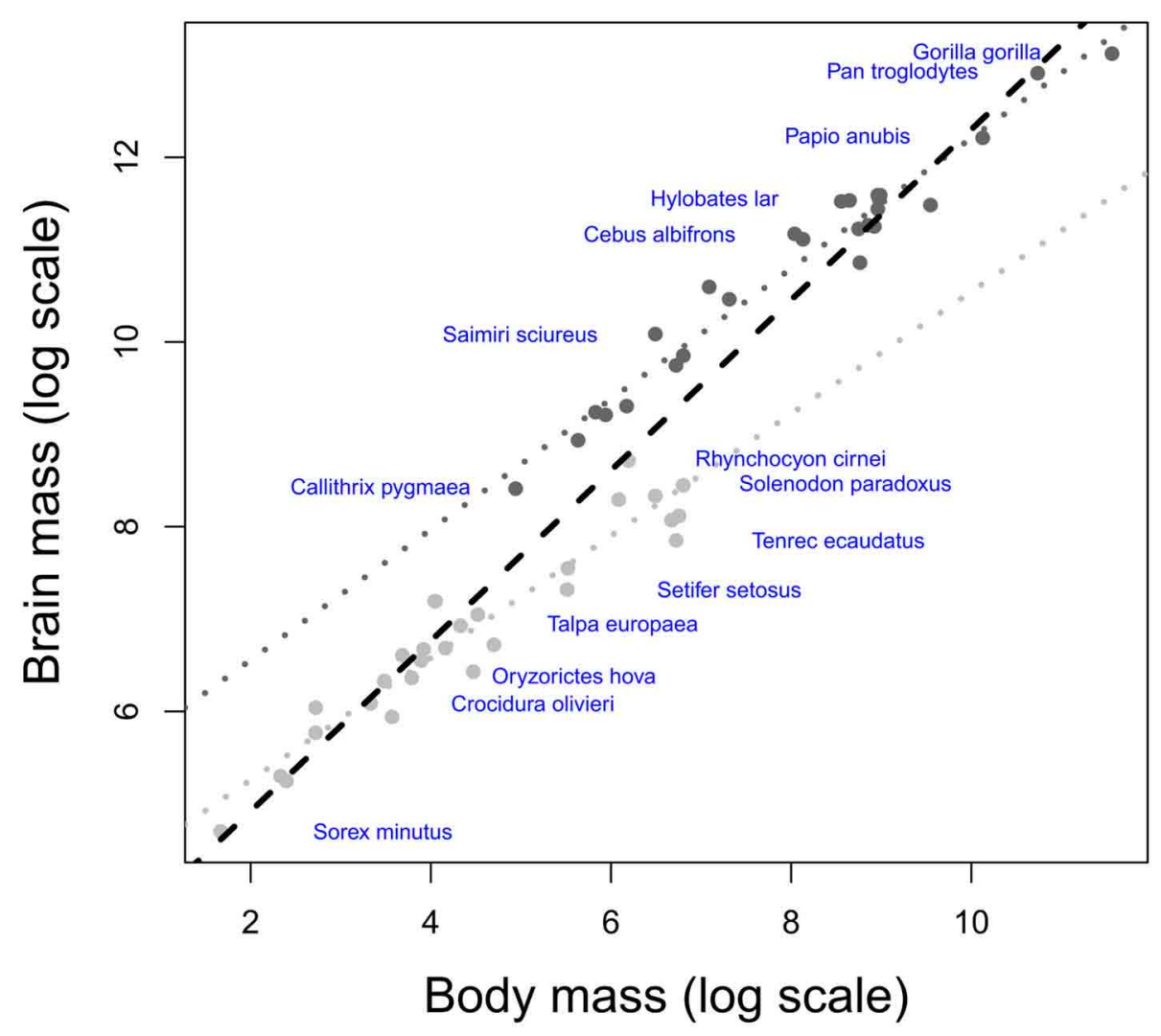

FIGURE 1 | Scatter plot of brain weight onto body weight (log scale) in insectivores (light gray) and simians (dark gray). Humans have been excluded from the analysis due to their large encephalization quotient (Rilling, 2006; but see Herculano-Houzel and Kaas, 2011). The dotted lines represent the respective brain/body allometric slopes for each taxon, and the black dashed line represents the common allometric slope. Note that when using a common slope; the largest brained simian species possess negative residuals, whereas the smallest brained insectivore species possess positive residuals. 
2012). Consequently, "the fact that elephant and whale brains are several times larger than human brains" (see Introduction) is, by itself, uninformative on their respective cognitive abilities. Iwaniuk and Hurd (2005) have shown that bird species could also be grouped into taxon-cerebrotypes (following Clark et al., 2001). Interestingly, Figure 2 suggests that, unlike mammalian taxa, the brain composition of Psittaciformes species is not predicted by their brain size. The range of brain size (13-folds between the smallest and largest brain of the Psittaciformes dataset, compared to 18,100 and 250-folds in Pteropodidae, simians (human species excluded) and carnivores, respectively, data from Reep et al. (2007), Stephan et al. (1981) and unpublished data from the same research group) is maybe too small to make a tendency visible, or species variability in Psittaciformes is particularly large. Should this observation be confirmed and generalized to other bird-cerebrotypes, it would suggest that both the factors underlying brain evolution inside a taxon and the methods needed to study them might differ between birds and mammals.

\section{REMARKS}

The EQ method has been used here because of its significant influence on brain studies and its popularity outside the scientific community. The problems highlighted above should affect every analysis in which datasets exhibit taxa-specific relationships between variables (for instance in the scaling of the basal metabolic rate with body size, (White et al., 2009, or the duration of the gestation period, Martin et al., 2005). Studies on brain composition at the bird or mammalian level will necessary produce inconsistent results [see for example Kaskan et al. (2005) and
Barton (2007) for opposite conclusions concerning the adaptation of the visual system in mammals and primates, respectively]. Indeed, even traditional groups such as bats, cetaceans, or primates are potentially subject to these inter-taxa characteristics (e.g., Willemet, 2012). Comparative methods such as phylogenetically independent contrasts (PIC, Felsenstein, 1985) are ineffective in dealing with this issue. The solution comes from the determination and analysis of taxon-cerebrotypes (Willemet, 2012).

\section{COMPARING TAXON AND SPECIES CEREBROTYPES TAXON-CEREBROTYPE DIFFERENCES}

For morphological and sensorial reasons, the quantity of information coming from and directed to the body should differ between taxa. Also, for ecological reasons, the nature of the information from the environment and the manner of analysing it should differ between taxa (see section Factors Underlying the Evolution of the Size and the Composition of Brains). Accordingly, an analysis comparing the size of each structure relative to the other structures in carnivores and simians (Table 1 and Figure 3, see also Figure 4) reveals significant differences between these two taxon-cerebrotypes [simian data from Stephan et al. (1981); carnivore data from Reep et al. (2007)]. Moreover, and in addition to the fact that simian species possess a brain around twice as large as carnivore species of similar body weight [data from Kirk (2006) and Finarelli and Flynn (2009)], a carnivore brain differs from a simian brain in many other characteristics. For example, except for small species, simians have a bigger frontal cortex than carnivores for a similar size of the rest of

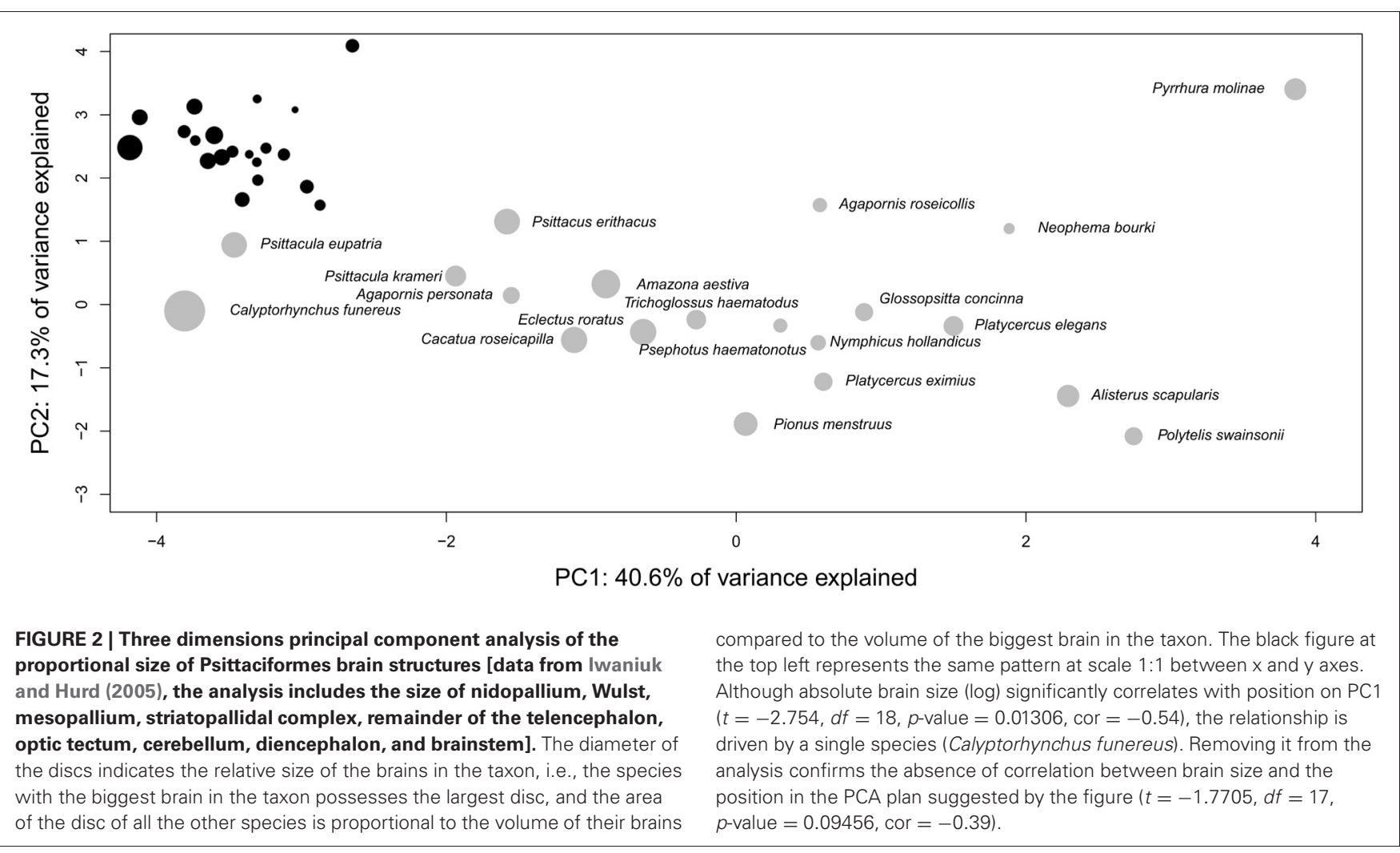


Table 1 | Differences between carnivore and simian cerebrotypes (human species excluded).

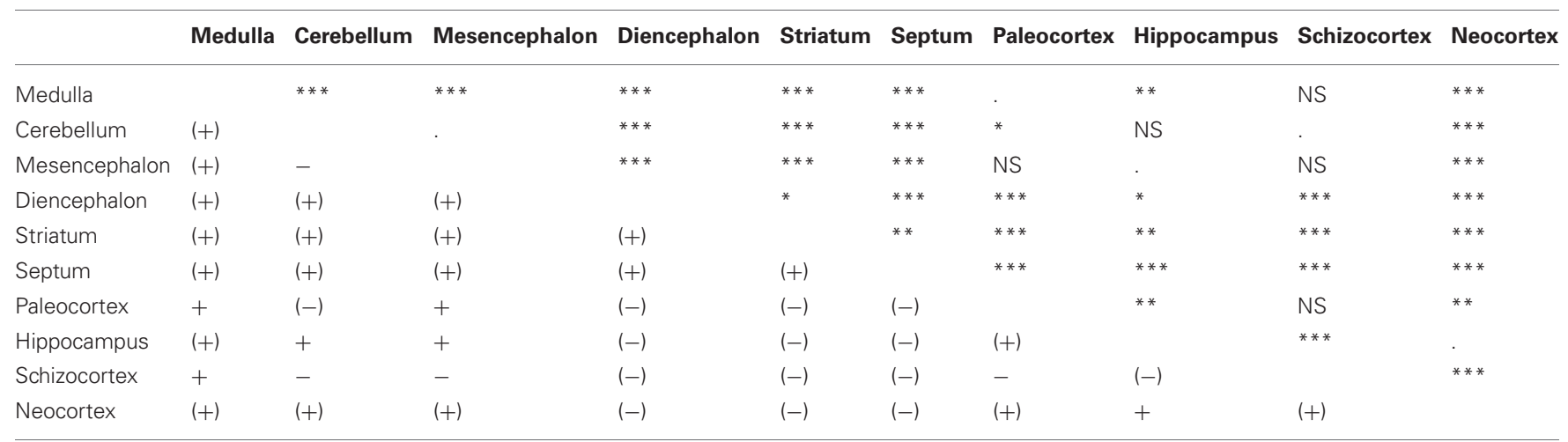

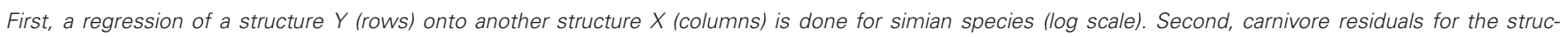

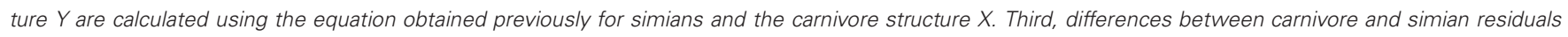

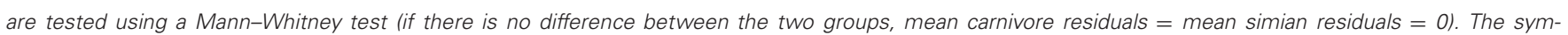

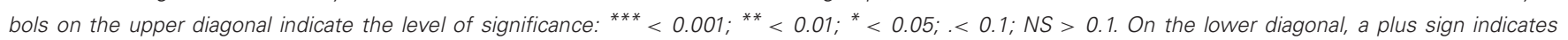

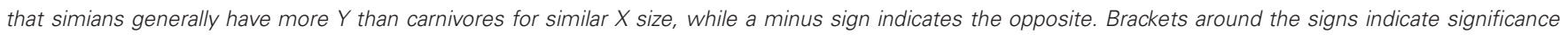

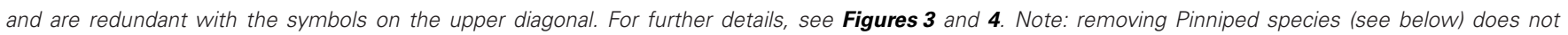

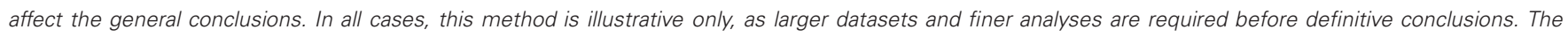

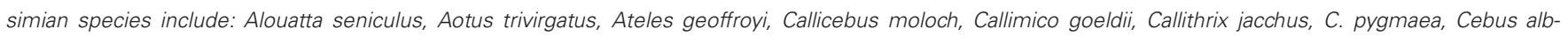

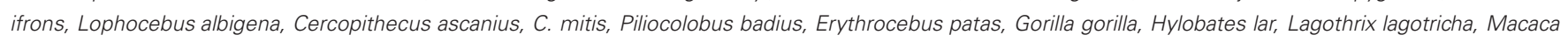

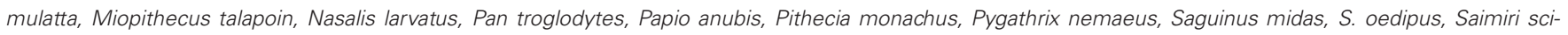

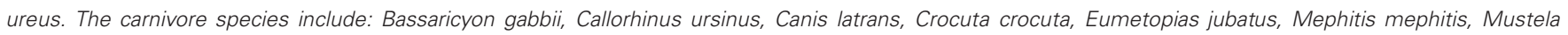

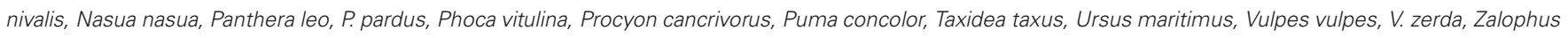
californianus.

the neocortex (Bush and Allman, 2004, the term "neocortex" has been preferred here against "isocortex" following Butler and Hodos, 2005). Also, carnivore and simian cerebrotypes differ in the pattern of neocortex girification (Pillay and Manger, 2007) and cortical layering (Hutsler et al., 2005). In fact, it is likely that differences between these two taxon-cerebrotypes affect most neuroanatomical levels. Distinguishing taxon-cerebrotypes and species-cerebrotypes differences is fundamental in understanding how brains control species differences in cognition and behavior. In this regard, the nuclear arrangement of the avian pallium offers an interesting evolutionary alternative to the mammalian neocortex (Güntürkün, 2005, 2012). It is important, however, not to systematically generalize observations from one taxoncerebrotype to others (Striedter, 2002).

\section{METHODOLOGICAL ISSUES}

There are several difficulties inherent in allometric analyses. First, researchers must distinguish between characters (potentially) shared by all mammalian species and taxa or species-specific evolutionary specializations. A particularly compelling example of this issue is the spindle like cells that were originally thought to be unique to apes and humans (Nimchinsky et al., 1999), but that have then been discovered in the large brained species of virtually all mammalian taxa (Butti et al., 2011). Second, researchers must distinguish between the confounding effects of the relative and absolute size of the structures. For example, Reep et al. (2007) hypothesized that "perhaps the reduction of the olfactory system in primates and humans is the unfortunate but tolerable result of selection to increase the size of the isocortex by reassigning stem neurons from olfactory bulb and hippocampus to the isocortex" (see also Yopak et al., 2010). But do primates (or simians) possess relatively small limbic structures? It actually depends on relative to what (Figure 4, see also Smith and Bhatnagar, 2004 and Heymann, 2006 for interesting discussions on olfaction in primates). In fact, the apparent trade-off described by Reep et al. (2007) is due to differences in the structure relative sizes. Although in simians, the enlargement of the neocortex (and cerebellum) has largely outweighed the enlargement of other structures, it does not constitute proof of a "push-pull relationship", since there is no evidence that the selection of the limbic structures has been constrained by the selection of a large neocortex. Therefore, understanding the differences between species and taxon cerebrotype requires the use of precise methods, able to examine the variations of single brain structures and systems, at the species and group level.

\section{FACTORS UNDERLYING THE EVOLUTION OF THE SIZE AND THE COMPOSITION OF BRAINS}

Although understanding the factors underlying species differences in brain size and composition is a key issue in evolutionary neuroscience, our current understanding of it is limited. Nowadays, the "passive growth" of Aboitiz (1996) is considered to be "the main determinant of brain size across species" (Aboitiz, 2001). Under this view, the "brain increases in size by virtue of genetic and developmental coupling with the rest of the body"; a process that "does not necessarily imply higher processing capacity" (Aboitiz, 2001). Striedter (2006) suggested that "evolutionary changes in absolute brain size $[\ldots]$ are an 

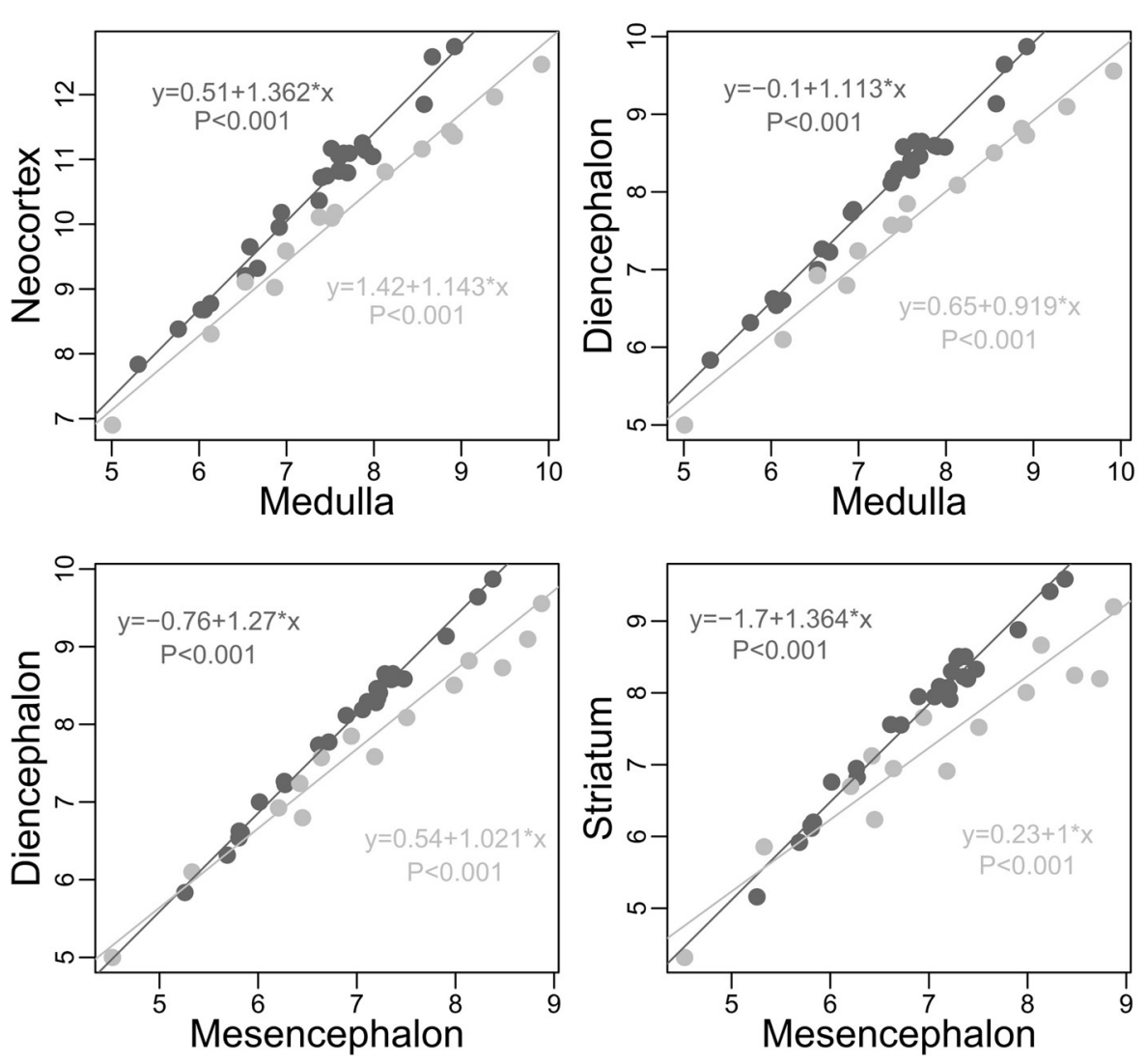

FIGURE 3 |Plots of some of the most obvious differences between carnivores (light gray) and simians (dark gray, human species excluded) cerebrotypes (log scale). On average (although an average is inappropriate due to slope differences), for similar medulla sizes, simians possess a neocortex and a diencephalon 2 times larger than carnivores (neocortex: Minimum 1.323, 1st Quartile 1.506, Median 2.007, Mean 2.047, 3rd Quartile 2.322, Maximum 3.509; diencephalon: Min. 1.362, 1st Qu. 1.611, Median 2.001,

Mean 1.981, 3rd Qu. 2.150, Max. 2.785). On average again, for similar mesencephalon size, simians possess a diencephalon and a striatum, respectively, 55 and 85 percent larger than carnivores (diencephalon: Min. 0.9346, 1st Qu. 1.3890, Median 1.5660, Mean 1.5480, 3rd Qu. 1.7180, Max. 2.1880; striatum: Min. 0.7174, 1st Qu. 1.5750, Median 1.8810, Mean 1.8500, 3rd Qu. 2.2310, Max. 2.6490). Slope differences between these two taxa, unobserved in Willemet (2012), are clearly visible here.

'automatic' consequence of changing body size" (original quotation marks) and that "increasing absolute brain size 'automatically' changes the proportional size of the individual brain regions" (Striedter, 2006, original quotation marks). Under this view, the evolutionary significance of brain structure size in terms of cognitive abilities would be at best indirect, as its evolution would depend on factors others than those selecting for cognitive abilities. Indeed, Deacon (1990a) considered that "brain size [...] is at best a hypothetical correlate of some poorly understood mental parameters (e.g., intelligence, memory), which themselves are only hypothetically correlated with any ecological parameter and are highly canalized and inflexible in development." More recently, referring to the large proportion of the neocortex in big brained mammalian species, Barton suggested that "whilst it might be tempting to speculate on the hitherto unappreciated intelligence of these species, the most parsimonious explanation is that they are just large animals" (Barton, 2012). Yet, instead of being strongly anchored in an empirical and theoretical framework, such a view arose from misconceptions on the significance of allometric relationships. Firstly, the fact that two variables (here, brain and body size) allometrically correlate does not imply that one variable (body size) controls the other (brain size). Second, brain size is no more than the cumulative size of the structures that constitute it. Therefore, it is probably more correct to consider that brain structure sizes control brain size, rather than the reverse. In this section, and even though much more work is needed to understand the factors influencing size variations of each brain structure (thereby controlling both brain size and composition), several factors playing a role in the selection of brain structures (in particular the neocortex and cerebellum) are presented.

\section{SOMATIC FACTOR}

Even though the correlation between brain and body size in mammals and birds has long been recognized (e.g., Dubois, 

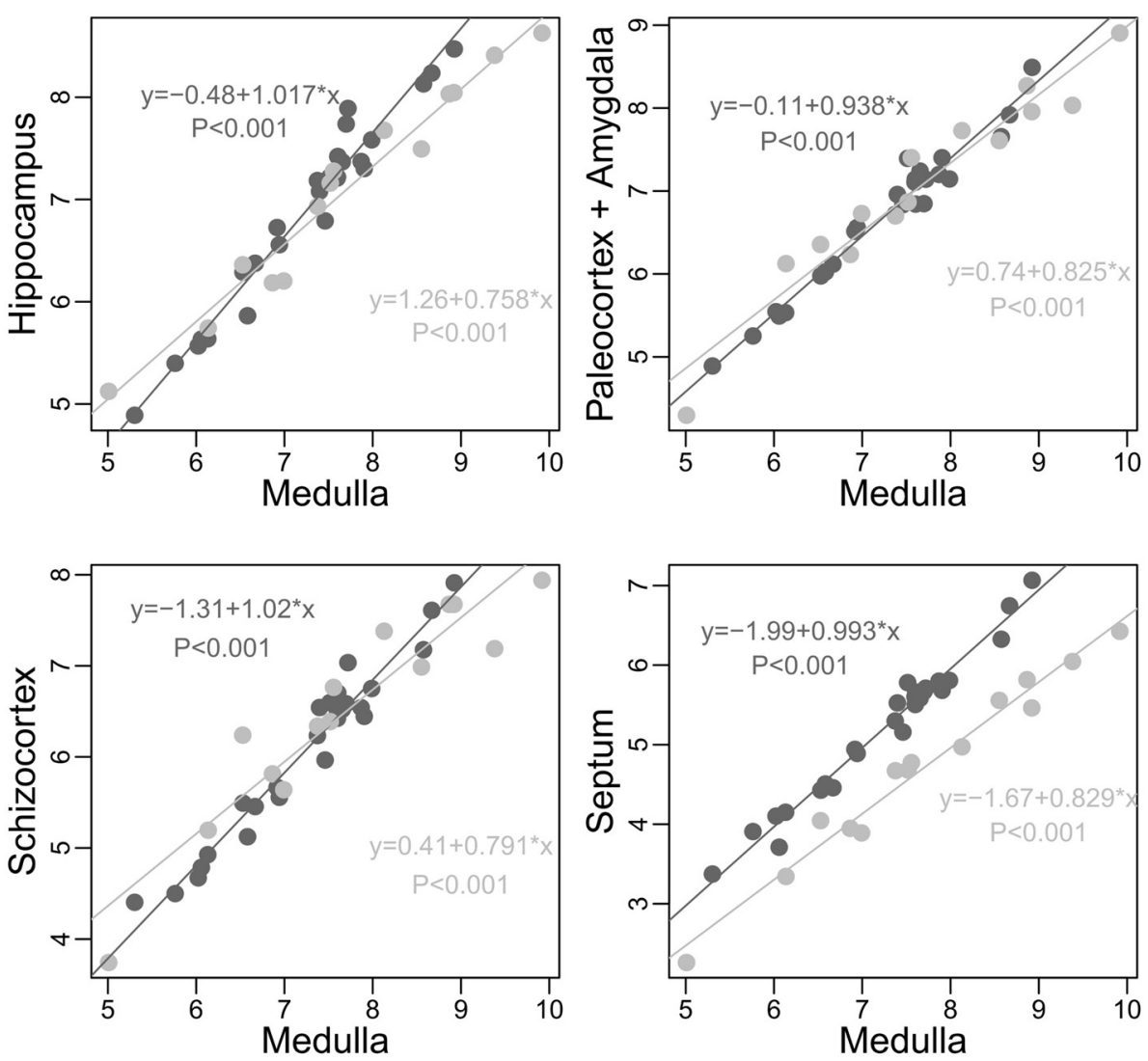

FIGURE 4 | Scaling of limbic structures onto medulla (log scale) in carnivores (light gray) and simians (dark gray). To strengthen the point, pinnipeds species are not included in this analysis (pinnipeds apparently have smaller hippocampus, paleocortex, and amygdala than fissipeds of similar medulla size, but similar septum and schizocortex size, unpublished analysis). In no cases does simians as a group have smaller limbic structures than predicted by the size of their medulla when compared to carnivores (differences between the actual size of the structure and the expected size predicted by carnivore allometry; hippocampus: Min. 0.6793, 1st Qu.0.9240, Median 1.2180, Mean 1.2010, 3rd Qu. 1.3930, Max. 2.1860; paleocortex: Min. 0.7696, 1st Qu.0.8467, Median 0.9241, Mean 0.9918, 3rd Qu.1.1050, Max. 1.5790; schizocortex: Min. 0.6056; 1 st Qu.0.7367; Median 0.9523; Mean 0.9787; 3rd Qu. 1.0800; Max. 1.6810; septum: Min. 1.434, 1st Qu. 2.119, Median 2.383, Mean 2.442, 3rd Qu. 2.646, Max. 3.830). See also Table 1
1897), the reasons for this relationship have, as emphasized above, always remained unclear. An obvious but important factor is that the brain must fit into the skull (Striedter, 2005), so that only large animals can support large brains. However, this fact alone cannot explain why large animals often have large brains. It has been hypothesized that "larger organisms, which generally have larger organs, need to have larger brains in order to control and service the increasing somatic and vegetative demands that are inevitable consequences of increases in body size" (Hofman, 1989). In agreement with this hypothesis, spinal cord size rises with body size in mammals (MacLarnon, 1996). This "somatic factor" (Jerison, 1973) is the first reason for which we can expect a concerted pattern of evolution inside taxoncerebrotypes. Consistent with this approach is the fact that brain size scales more tightly with fat-free body weight than fat weight (a poorly innervated tissue) in a dataset of 19 rodent species (Schoenemann, 2004). This hypothesis seems valid for the structures primarily implied with somatic function, but not sufficient for explaining the enlargement of the neocortex and cerebellum in particular.
Stevens (2001) has shown that, in primates, the number of neurons (and the size) of the primary visual cortex scales with a positive allometry compared to the number of neurons of the lateral geniculate nucleus because as eyes get bigger in species, the linear resolution of distances in the visual world also increases, and in order to maintain the same spatial resolution in the neocortex, the number of cortical neurons must increase with positive allometry compared to the neuron number in the lateral geniculate nucleus (the visual center of the thalamus). Thus, part of the coordinate increase between brain and body size could be related to this kind of functional constraints (see also Collins et al., 2013). A study of the allometric relationship at the cellular scale of the primate's brain and spinal cord indicates that although brain mass increases linearly with cord mass, the number of neurons in the brain increases faster than the number of neurons present in the spinal cord (exponent of 1.7, Burish et al., 2010). While this result could be consistent with the functional hypothesis presented above, some associative areas of the brain exhibit a positive allometry compared to other areas in primates (for example the prefrontal cortex, e.g., Smaers et al., 2011a). 
This suggests that other factors participate in the enlargement of structures.

\section{NON-SOMATIC FACTORS}

Although it is clear that no researcher ever considered the brain just as the body's control center, most authors have adopted methods that explicitly consider the somatic factor as the most important function of the brain. For example, residual analyses or multiple regressions are used to control for "body size effects" (e.g., Iwaniuk et al., 2004), and most authors would agree that "the strongest driver of brain size is body size" (Changizi, 2010). However, brains guide individuals inside their ecological and social environment (Umwelt), body control being an important, but non-exclusive, part of this duty. Therefore, any species' brain possesses more processing capacity than those required to process body functions. The idea of dividing the brain in one part dedicated to cognition and another to body control is not new and has been criticized on the basis that discrete anatomical division is unlikely (Deacon, 1990a). In fact, both parts are probably linked in many ways. As Barton (2012) phrased it: "the evolution of large brains was associated with the elaboration of sensory-motor mechanisms for the adaptive control of bodies in their environments." It is nonetheless possible to distinguish between the two in formulating the hypotheses on the factors underlying brain evolution. Indeed, what are the non-somatic factors that could have played a role in the evolution of brain size and composition?

\section{Longevity}

The variable "body size," often represented by body weight, is only an approximation of a size factor (not necessarily a good one, Harvey and Krebs, 1990; Burish et al., 2010). This "size factor" is actually much more than a simple morphological variable and involves the allometric scaling of many other lifestyle variables. Of particular interest here is the observation that big mammals live longer than smaller mammals (Speakman, 2005). Logically, absolute brain size correlates with longevity (Sacher, 1959, Table 2 of Allman et al., 1993). Merker (2004) proposed that the size of the neocortex is an adaptation for the long term storage of contextual information needed throughout a species' lifespan. This hypothesis is close to that of Allman et al. (1993) with the major difference that Merker's account concerns the absolute size of the brain (or more exactly, the neocortex) correlating with absolute lifespan, and not their relative values. The original hypothesis of Allman et al. (1993) can in fact be adapted without even modifying the authors' original words: "one of the important functions of the brain is to store information about resources in the environment so that the organism can survive occasional catastrophes by switching to alternative resources. The longer the life-span of the animal, the more likely it is to encounter severe crises during its lifetime. Thus, it might be expected that species with longer life-spans would have larger brains in order to sustain individuals through the more severe crises likely to occur in a longer life" (Allman et al., 1993). Under this view, the large neocortices of big bodied mammals are an obligatory feature that permits the long-term storage of their longer "personal history" (Merker, 2004). Interestingly, the neocortex enlargement is coupled with the cerebellum enlargement (Barton, 2002, see also Sultan, 2002;
Herculano-Houzel, 2010; Smaers et al., 2011b). In fact, in addition to its role in motor control, the cerebellum plays a role in many other cognitive functions (Ramnani, 2006), and it has been suggested that these two structures operate together, under a cerebro-cerebellar system (Leiner et al., 1991). Imamizu et al. (2000) have found that, in humans, the cerebellum possesses an internal model of new tools after learning. Given that a bigger lifespan implies more situations of learning, the enlargement of the cerebellum is compatible with the view that a fraction of brain enlargement responds to the need for storing the quantity of knowledge that goes along with longer lifespan. However, the relevance of the storage hypothesis is likely to vary across taxa. For example, it might be less relevant in bats (chiroptera), who have both small brains and a relatively high longevity (e.g., Brunet-Rossinni and Austad, 2004).

\section{Information processing capacity}

Many hypotheses on the cognitive factors that play a role in the evolution of the size and the composition of brains have been proposed. These hypotheses are traditionally separated into two categories; ecological [the spatiotemporal mapping hypothesis, Clutton-Brock and Harvey (1980); the foraging hypothesis, Milton (1981), Gibson (1986); the technical intelligence hypothesis, Parker and Gibson (1977), Byrne (1997)] and social (the social intelligence hypothesis, Humphrey (1976), Byrne and Whiten (1989), Dunbar (1998); the relationship intelligence hypothesis, Emery et al. (2007) [but see Scheiber et al. (2008); the cultural intelligence hypothesis, van Schaik et al. (2012)], although the two are sometimes linked (Dunbar and Shultz, 2007). Sensory motor factors have also probably played a role in the evolution of cognitive capacities via, for example sensory control of skilled movements (Whishaw, 2003; Sultan and Glickstein, 2007) or sensory adaptations (Paulin, 1993; Barton, 1998, 2004). Indeed, as stated by Barrett (2011) "An adaptive fit between an organism and its environment can also be achieved through selection for a capacity that allows animals to continually update their knowledge of the world." In addition, there are evidences that body size could influence a species' cognition and behavior (Dial et al., 2008). Charvet and Finlay (2012) have suggested that the longer developmental time needed to construct larger brains and the extended learning period associated with it should be viewed as a factor in brain evolution. Therefore, it is possible that the factors reviewed above act differently on altricial and precocial species.

Each ecological niche is characterized by a certain combination of these factors. The adaptative approach presented here postulate that the respective importance of these factors should be partly visible in evolution of the brain architecture. In fact, there is direct evidence that increasing cognitive capacities have been a driving factor in brain evolution among simians. First, Bush and Allman (2004) have shown that the frontal cortex scales with positive allometry relative to the rest of cortex in primates while it does not in carnivores. Second, Balsters et al. (2010) have measured the volumes of cerebellar lobules in structural MRI scans for capuchins Cebus apella, chimpanzees Pan troglodytes and humans and have found a tendency for the lobules related to prefrontal cortex to get relatively bigger into the simian's cerebellum 
as the brain gets bigger. Although a definitive conclusion would require an appropriate dataset, this impression is supported by the macaque monkey Macaca mulatta measure that fits between the ones of the capuchin and the chimpanzee, as predicted by its intermediate brain size. Interestingly, there are direct pathways between the neocortex and medulla that become increasingly important with brain size in simians (Striedter, 2005). This suggests that, in simians, selection for higher processing capacity is also linked to a better cognitive control of the body inside the environment (see also Wilson, 2002; Barton, 2012).

It is important to note, however, that developmental and functional constraints could limit the extent to which brain regions can be selected individually. The neocortex, in particular, is divided in areas devoted to a particular set of information (see Krubitzer and Seelke, 2012 for an overview of their evolution) and there is a correlation between neocortex size and the number of neocortical areas across mammals (Changizi and Shimojo, 2005; Striedter, 2005) due to the constraints of maintaining neuronal connection when neuron number increases (Ringo, 1991). As neocortex gets bigger, higher order cortical areas emerge from core fields (Rosa and Tweedale, 2005, see also Kirkcaldie and Kitchener, 2007), leading to a better treatment of neural information (Striedter, 2005, but see Kaas, 2000). It is possible that, due to developmental and functional constraints, selection for some functions supported by the neocortex has consequences on the whole structure [but see Welker and Seidenstein (1959) for a counterexample]. In addition, it is possible that, compared to smaller ones, bigger structures are better able to integrate new functions (via neural reuse for example, Anderson, 2010) without a correlated increase in size.

Although much more work is needed to unravel the mechanisms and factors responsible for the evolution of brain composition, the approach presented here strongly contrasts with the traditional (allometric) approach presented above, in particular by giving a direct adaptive value for the size of each brain region. Moreover, this approach undermines the hypothesis that variations in brain structure sizes are solely the consequence of their position on the prosomeric axes (Finlay et al., 2001) and will ultimately permit understanding of the full complexity of the developmental model (including the cerebellum "exception" of the "late equals large" model). Other factors, cognitive or not, are likely to be added on the list of factors influencing the evolution of the size and the composition of brains. For example, the hypothesis of "adaptive redundancy," which postulates that in larger brains "memories are written into multiple circuits to protect against interference or injury" (Chittka and Niven, 2009) can be extended to the whole range of cognitive process. It is also possible that the robustness associated with larger brains is physiological (in terms of blood flow, glucose reserve, etc.). Also, under the view developed above, the evolution of brain structure sizes in taxon-cerebrotypes is concerted mainly because species are under similar selection pressures. Importantly, the concerted pattern hides a host of species-specific adaptations in brain composition that further adapts each species to its own environment (see Krebs et al., 1989; DeVoogd et al., 1993 for early references). However, most studies on this issue should be re-evaluated in regard of the points discussed here, in particular the importance of examining both the absolute and relative size of a brain region (see also section Brain Composition and Cognition). It follows from above that the variable "brain size" should therefore be used with caution; as it hides the real variables under selection, the structures (see also Healy and Rowe, 2007).

\section{RELATIVE BRAIN SIZE}

The preceding section has shown that body size is only one among many other variables influencing brain size. Therefore, although encephalization is a multidimensional variable (dependent on all the cognitive, environmental and lifestyle factors associated with brain and body size), the EQ reduces it to a bidirectional (brain/body) approach. The true meaning of such an approximation has yet to be defined; in particular in view of the interest researchers have for it (e.g., Lefebvre, 2012 for a recent review in primates). For example, which structures participate in the relative (compare to body size) variations in brain size? A relatively enlarged brain is thought to represent "selection for enhanced processing capacity" (“active growth” Aboitiz, 2001). If true, what fraction(s) of the processing capacities have been favored, or reduced (long-term storage, sensory motor, or association capabilities) with encephalization? How do variations in structure size correlate with lifestyle variables?

\section{BRAIN COMPOSITION AND ENCEPHALIZATION}

The approach presented above predicts that species with relatively larger brains present specific modifications in the taxoncerebrotype allometry reflecting the structures having been selected (see also Aboitiz, 1996). Early support for this hypothesis is found in Barton (1998) who reported that relative neocortex size correlates positively with the EQ. Crucially, the extent to which a structure participates in brain size variation depends on its relative and absolute size (see also Lefebvre et al., 2006). For example, in a hypothetical species with a $100 \mathrm{~g}$ brain, selection for the functions supported by a structure doubled the size of this structure from 5 to $10 \mathrm{~g}$ (changing its proportion from 5 to $9.5 \%$ ). This species, although with a structure two folds bigger than the ancestral condition, still possesses a brain of almost the same size, $105 \mathrm{~g}$. Because brain size has been almost unchanged, this adaptation is nearly invisible for analyses using absolute brain size or encephalization residuals. On the contrary, a 2-fold augmentation of a $50 \mathrm{~g}$ structure raises brain size from 100 to $150 \mathrm{~g}$, one and a half initial brain size, whereas the structure's relative proportion goes from 50 to $66 \%$, an augmentation of 1.3 only. Therefore, changes in the largest structures are the most likely to be detected by encephalization studies (and to cause changes in absolute brain size, see section Factors Underlying the Evolution of the Size and the Composition of Brains). To address this point, one can test the correlation between deviations from structure size allometry and encephalization residuals. The analysis, carried out in three relatively homogenous taxon-cerebrotypes: carnivores, simians, and the chiroptera's family Pteropodidae (see Willemet, 2012), suggests that the neocortex is not the only structure modified during encephalization, although larger datasets and phylogenetic methods are needed before definitive conclusions can be drawn (Table 2, Figure 5). 
Table 2 | Results of regression of residuals of the size of one structure against the size of another structure onto encephalization residuals.

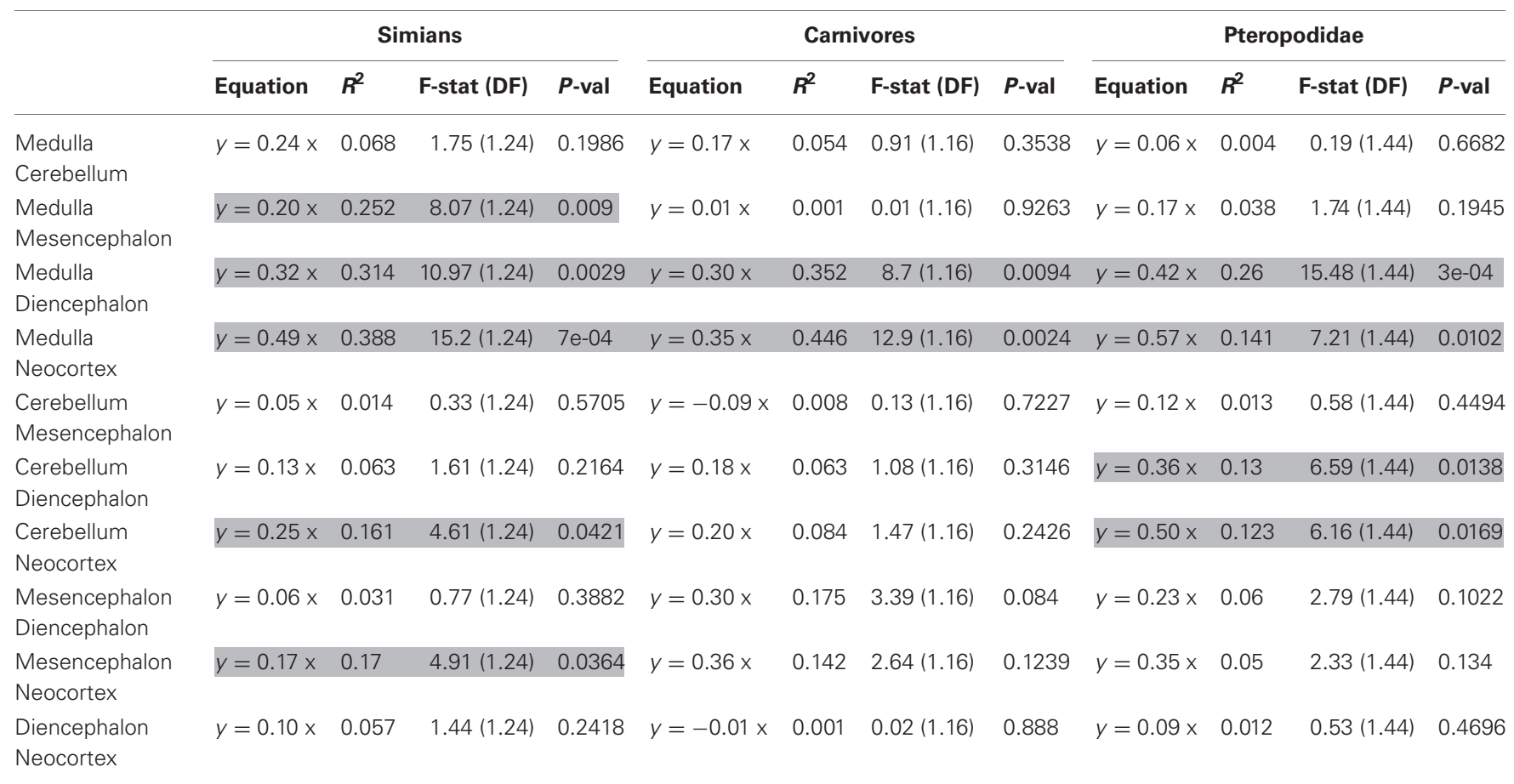

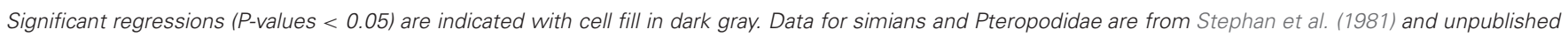

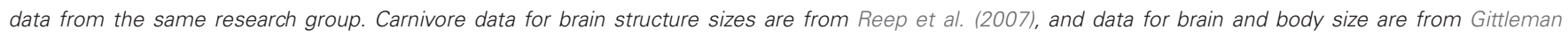

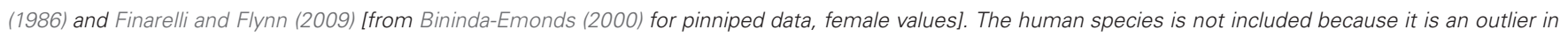
encephalization residuals. For further details, see Figure 5.

The significant relationships between brain composition and relative brain size suggests that variations in relative brain size are at least partly due to similar pressures between species (it is likely, however, that the factors controlling variations in brain structures differ between these taxa). This finding, if confirmed, is interesting given that the method used here does not distinguish between changes in relative brain size that are due to enlargement of the brain and changes that are due to reduction of the body (but see Montgomery et al., 2010 and Smaers et al., 2012a). In particular, the correlations between structure deviations and encephalization residuals in simians could provide insight into some species characteristics, like the relatively large cerebellum of gorillas Gorilla gorilla (Rilling and Insel, 1998; Semendeferi and Damasio, 2000; Sherwood et al., 2004). Inversely, these results suggest that the human cerebrotype is closer to the simian cerebrotype than predicted by its EQ (not shown here), despite some claim about it having a relatively large neocortex (Rilling and Insel, 1999). This suggests that there has been selection toward a relatively large cerebellum in modern humans, as also suggested by the reciprocal evolution of the cerebellum and neocortex during human evolution (Weaver, 2005). These results further support the approach presented in section Factors Underlying the Evolution of the Size and the Composition of Brains and suggest that the interpretation that relative brain size is a factor of brain evolution (e.g., Smaers and Soligo, 2013) ought to be re-evaluated and considered to be a consequence of brain evolution. How each structure reacts to selection is difficult to interpret from this analysis because the reference used to determine the variations is the relative size of the brain itself. An alternative to the use of brain and body size, and one possible way to evaluate the quantity of brain relative to the somatic factor could be to use the spinal cord as a predictor (see also Burish et al., 2010 and Herculano-Houzel, 2011a). Deviations from structure size/spinal cord allometry could be a better way to measure the selection process of brain structures than deviations from brain/body allometry because it would allow the detections of changes in all brain structures, irrespective of their size. Unfortunately, published data on the spinal cord is scarce (MacLarnon, 1996; Burish et al., 2010). Finally, although Herculano-Houzel (2007) has suggested that neuron number in brain structures is independent of the EQ in rodents, larger datasets are needed to examine whether the selective pressures linked to the EQ produce distinct changes in structure composition.

\section{COGNITIVE FACTORS}

It follows from the above that the selective pressures responsible for a brain's relative size should in fact mainly target the functions supported by the neocortex (and to a lesser extent, the cerebellum) and therefore, affect species' processing capacities. It is unclear; however, which part(s) of the processing capacities (cognitive, sensory-motor, information storage) is/are favored (or reduced) by variations in encephalization.

The storage hypothesis is grounded on neocortical organization (Merker, 2004), so that any increase in neocortex size should lead to an increase in brain storage capacity, even without direct selection for it. Indeed, relative brain size correlates with relative 

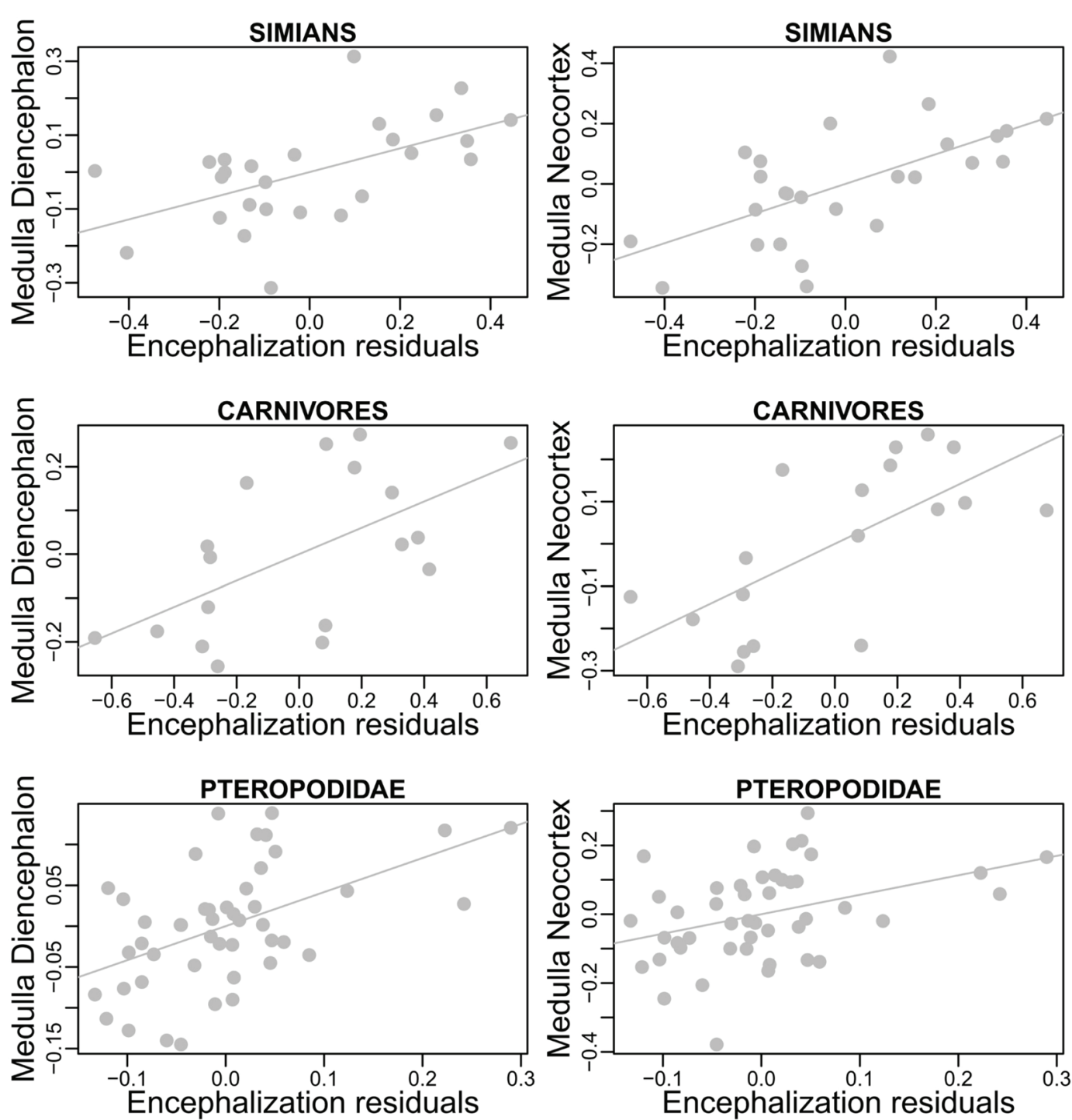

FIGURE 5 | Details from Table 2. Residuals from regressions of diencephalon (left) and neocortex (right) size onto the size of the medulla regressed onto encephalization residuals.

lifespan in primates (Allman et al., 1993; Barrickman et al., 2008). As the precise architecture of the cortico-cerebellar system and the mechanisms underlying information storage are uncovered, it will be possible to test this hypothesis more precisely.

Selection toward sensory-motor capacities could be one of the factors underlying changes in relative brain size. As discussed in section Non-somatic Factors, larger neocortex size could automatically lead to finer sensory motor representation, again even without direct selection for it. For some species it is also possible that larger brains have been selected specifically for increasing sensory-motor capacities in one or several modalities. For example, Barton (1998) showed a correlation between relative brain size and the size of the parvocellular pathway of the lateral geniculate nucleus (a visual center of the thalamus involved in the analysis of fine detail and color) in primates (see also Barton, 2004). Similarly, the relative amount of visual input correlates with relative brain size in primates (Kirk, 2006, see also Garamszegi et al., 2002). It is unclear, however, the extent to which selection for superior sensory-motor abilities can lead to increase in absolute (and therefore, relative) brain size. For example, although the North American raccoon Procyon lotor has a very large forepaw cortex that matches the extensive use of its hands (Welker and Seidenstein, 1959), there is no evidence that such a change can lead to a significant increase in brain size.

The most studied factor of encephalization is the cognitive buffer hypothesis, in which a relatively enlarged brain "facilitates the construction of behavioral responses to unusual, novel or complex socioecological challenges" (Sol, 2009). As for the storage and sensory-motor hypotheses, the cognitive buffer 
hypothesis could partly be a necessary consequence of increased neocortex size. Unfortunately, support for the cognitive buffer hypothesis often comes from studies that have mixed several taxa, and thus, several taxon-cerebrotypes [reviewed in Healy and Rowe (2007)]. Furthermore, for reasons that follow the discussion above, and detailed in the next section, the EQ cannot be systematically linked with absolute measures of cognitive abilities. If the encephalization process were associated with increased cognitive capacities, then a positively encephalized brain should have greater cognitive capacities than a similarly sized brain with neutral encephalization. In primates, the Pearson correlation test between residuals from the regression of an estimate of general cognitive ability onto the size of the brain on one side, onto encephalization residuals calls for further studies $(t=1.9854$, $d f=21, p$-value $=0.06032$, cor $=0.4$, psychological data from Deaner et al., 2006). Notwithstanding the fact that the precision of the data is critically small and that many factors other than structure size control cognitive abilities (see sections Brain and Cognition; Species Differences in Cognition and Behavior), one of the reasons for this mixed result is the possibility that the size constraint has selected for mechanisms that increase brain efficiency in species with relatively small brains (Strasser and Burkart, 2012). A related hypothesis is that species that have undergone a decrease in brain size (see Montgomery et al., 2010) have kept some of the anatomical or physiological mechanisms evolved by their ancestor to counter the constraints of brain size (this could be an important factor in understanding the technology of the small brained Homo floresiensis, see for example Morwood et al., 2005). In all cases, searching for encephalization correlates is probably rendered difficult because many factors potentially influence brain structure sizes; to some extent in a species-specific way.

\section{CORRELATION BETWEEN BRAIN SIZE AND OTHER LIFESTYLE AND ENVIRONMENTAL VARIABLES}

While having a large brain is cognitively advantageous over a smaller one, the evolution of brain size has not been a oneway process (Niven, 2005; Safi et al., 2005; Montgomery et al., 2010; Smaers et al., 2012a). Many hypotheses on this issue suggest some kind of trade-off between brain (energetically expensive Aiello and Wheeler, 1995) and physiological or lifestyle variables. These hypotheses include metabolic constraints (e.g., Martin, 1981; Isler and van Schaik, 2006, but see Jones and MacLarnon, 2004), maternal investment (e.g., Martin, 1996; Finarelli, 2010; Barton and Capellini, 2011), neonatal maturity (Weisbecker and Goswami, 2011) and energy trade-off hypotheses [e.g., Aiello and Wheeler, 1995 (but see Hladik et al., 1999); Navarrete et al., 2011]. How these factors could influence brain size is discussed in their respective paper (see also section Methodological Issues).

However, the notion of "trade-off" to which these studies often refer is particularly difficult to test in a multidimensional world, as it entails more than a simple negative correlation between two variables. For example, although Pitnick et al. (2006) have found a correlation between relative brain size and mating system, adding only one variable to the analysis (morphological adaptation to foraging strategy) changes the allure of the results, with no correlation between testes mass and relative brain size
(Dechmann and Safi, 2009, see also Lemaître et al., 2009). By increasing (or decreasing) its quantity of brain, a species changes the exploitation of its environment as well as the lifestyle variables that are associated with these changes. Therefore, although the notion of ecological constraints on brain size is particularly compelling (e.g., Winkler et al., 2004), the notion of "tradeoff" should be called only when sufficient evidence supports it. Kotrschal et al. (2013) recently studied the possible trade-off between brain and gut size and offspring number. Although these results have been reported as "compelling experimental evidence for the cost of increased brain size," the "trade-off" discussed in the expensive tissue hypothesis results from a limited amount of resources for which brain and gut evolutionary "compete." In contrast, nutrients were abundant in Kotrschal et al. (2013) experiment, so the notion of cost has still to be precisely defined (see also Warren and Iglesias, 2012). Moreover, as discussed below, results from intra-species studies cannot be systematically transferred to the species level. The complex and interrelated relationships between all the cognitive, environmental and lifestyle variables, and brain and body size and composition constitute a global evolutionary strategy. This concept of strategy rectifies the notion behind the trade-off approach that all species hypothetically tend to have a bigger brain, but that only some can offer one because of the costs that it entails. Furthermore, it removes the apparent paradox that brain size could have cognitive implications while being determined by lifestyle constraints (Deacon, 1990a).

\section{BRAIN AND COGNITION BRAIN SIZE AND COGNITION}

In primates, by far the most studied mammalian taxon, several authors have recently suggested that absolute brain size could best explain species differences in cognitive abilities (Gibson, 2002; Deaner et al., 2007; Lee, 2007; see also Dunbar, 1992, but see Amici et al., 2010; Schmitt et al., 2012 and section From Cognition to Behavior: The Role of "Mentality"). This result was so counterintuitive that it is emphasized in the title of one of these influential papers "Overall Brain Size, and Not Encephalization Quotient, Best Predicts Cognitive Ability across Non-Human Primates" (Deaner et al., 2007). However, despite this new gain of interest toward absolute brain size (e.g., Marino, 2006), a coherent framework is still lacking.

As discussed in section Factors Underlying the Evolution of the Size and the Composition of Brains, absolute brain size (through the scaling of absolute features like the number of neurons and cortical areas and the structures' relative sizes) is linked to species differences in processing capacity. Yet, the somatic factor hypothesis suggests that the "amount" of processing capacity dedicated to somatic factors also increases with body size. Therefore, for two species of similar brain size, but of different body sizes, the cognitive advantage should be for the smallest bodied species. However, as illustrated in Figure 6, none of these two variables, absolute brain size or EQ, can potentially take the other into account.

More generally, it would be interesting to have, inside a taxoncerebrotype, an approximation of the fraction of brain size that responded to the extended somatic factor (that is, all the factors associated with body size) and the fraction dedicated to 


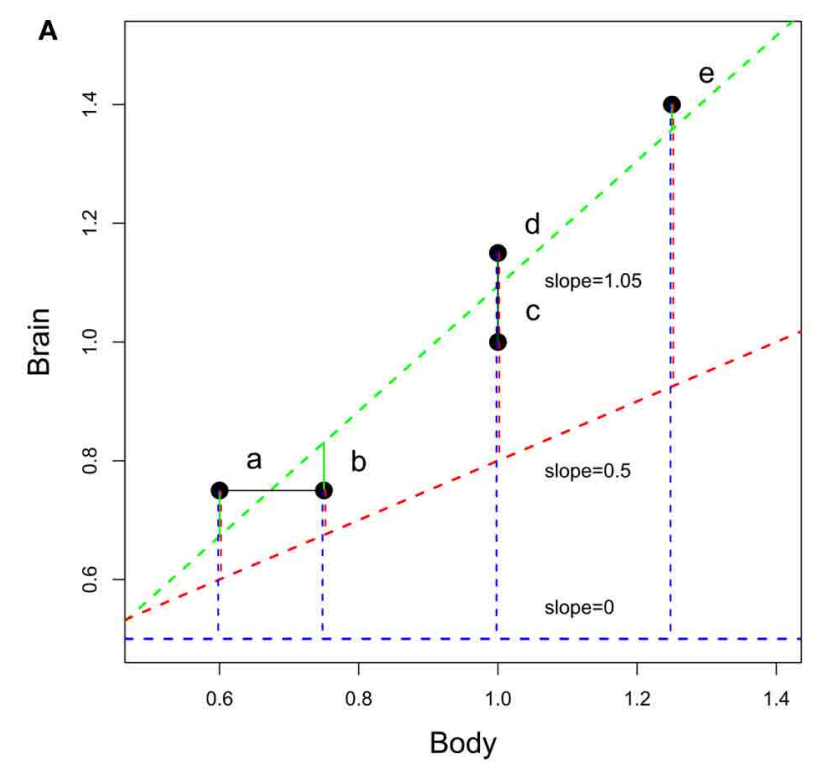

FIGURE 6 | Differences between encephalization quotient and absolute size in estimating species cognitive capacities. (A) Representation of the slopes. (B) Detail of the residuals (the scale is not respected between the 3 cases). At slope equals 1.05 (slope obtained by a regression of hypothetical brain and body size), encephalization quotient is insensitive to brain size. At slope between 0 and 1 , encephalization quotient is sensitive both to absolute

\section{B}

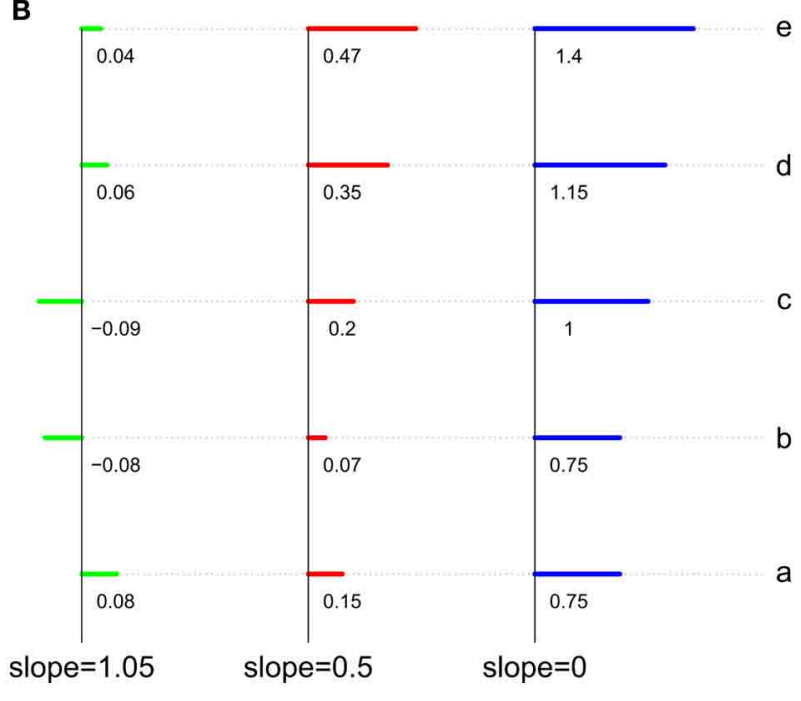

and relative brain size. At slope equals 0 , encephalization quotient equals absolute brain size. Although the preceding section has shown that brain size does not directly depend on body size, residuals have been computed using linear regression, the most used method for computing encephalization residuals (but see Warton et al., 2006 and O'Connor et al., 2007 for discussions on the regression methods used in comparative biology). cognitive function. One possible method is to observe the correlation between encephalization residuals and a general measure of cognitive ability when the value of the encephalization slope (and therefore the effect of body size on brain size) varies. Figure 7 represents this analysis carried out in primates, the only taxon (although significant differences between major primate impose finer analyses, see Isler et al., 2008; Willemet, 2012) for which a dataset vaguely corresponding to such a measure exists (Deaner et al., 2006).

Figure 7 corroborate earlier findings that brain size better predicts species cognitive ability than does EQ in primates and suggests that the extended somatic factor have played only a limited role on the evolution of brain size in primates. This is in accordance with the evidences presented in section Information Processing Capacity, which suggest that selection for large cognitive abilities played a major role in simian brain evolution. The results of this analysis appear to be counterintuitive; however, as body size appears to better predict cognitive capacities than brain size itself [as in Deaner et al. (2007)]. A part of this result is probably due to species-specific adaptations. Moreover, Deaner et al.'s (2006) data on species differences in cognitive abilities are neither accurate nor comprehensive. With quality data, the allure of this analysis in other taxa could be particularly interesting for understanding the relation between brain size (absolute and relative) and cognition. Indeed, it is possible that, in other taxa, most of the variation in brain size has resulted from selection to the extended somatic factor and that only species that had selection for more cognitive abilities have increased the size of the brain regions associated with it. In these taxa, the EQ (or residuals from a slope close to it) should better predict cognitive abilities than absolute brain size (although even in that case, the processing capacity added should differ between species, see Herculano-Houzel, 2007 for an explanation based on neuron numbers).

At the cellular level, Herculano-Houzel (2007) has first proposed that "the total number neurons in excess of the expected from body size in each species" would be an indicator of species cognitive abilities. However, such a method is subject to the same flaws as the EQ method discussed above. Due to their proportional scaling with the number of spinal cord neurons, the number of neurons "expected from body size" has then been approximated by the number of neurons in structures others than neocortex and cerebellum (Rest of Brain, RoB, HerculanoHouzel, 2011a). Because RoB neuron number is low compared to total brain neurons, the author went on to suggest that, in mammals, "the cognitive abilities of a species might be simply a function of its total number of brain neurons" (HerculanoHouzel, 2011a). However, neurons in the cortico-cerebellar system in particular are not equally distributed among taxa (e.g., Bush and Allman, 2004) and areas (e.g., Cahalane et al., 2012) and species differ in neuronal connectivity (DeFelipe et al., 2002), so that two brains with a similar number of neurons should differ in their processing capacity. Therefore, studies at the neuronal level will need to be particularly detailed, in the number of species, structures and cell types scanned, to reveal their whole potential.

In conclusion, the variables "brain" and "cognition" both represent a set of variables which are particularly complex (see also section Species Differences in Cognition and Behavior), so that any attempt to link these two "meta variables" will always be a 


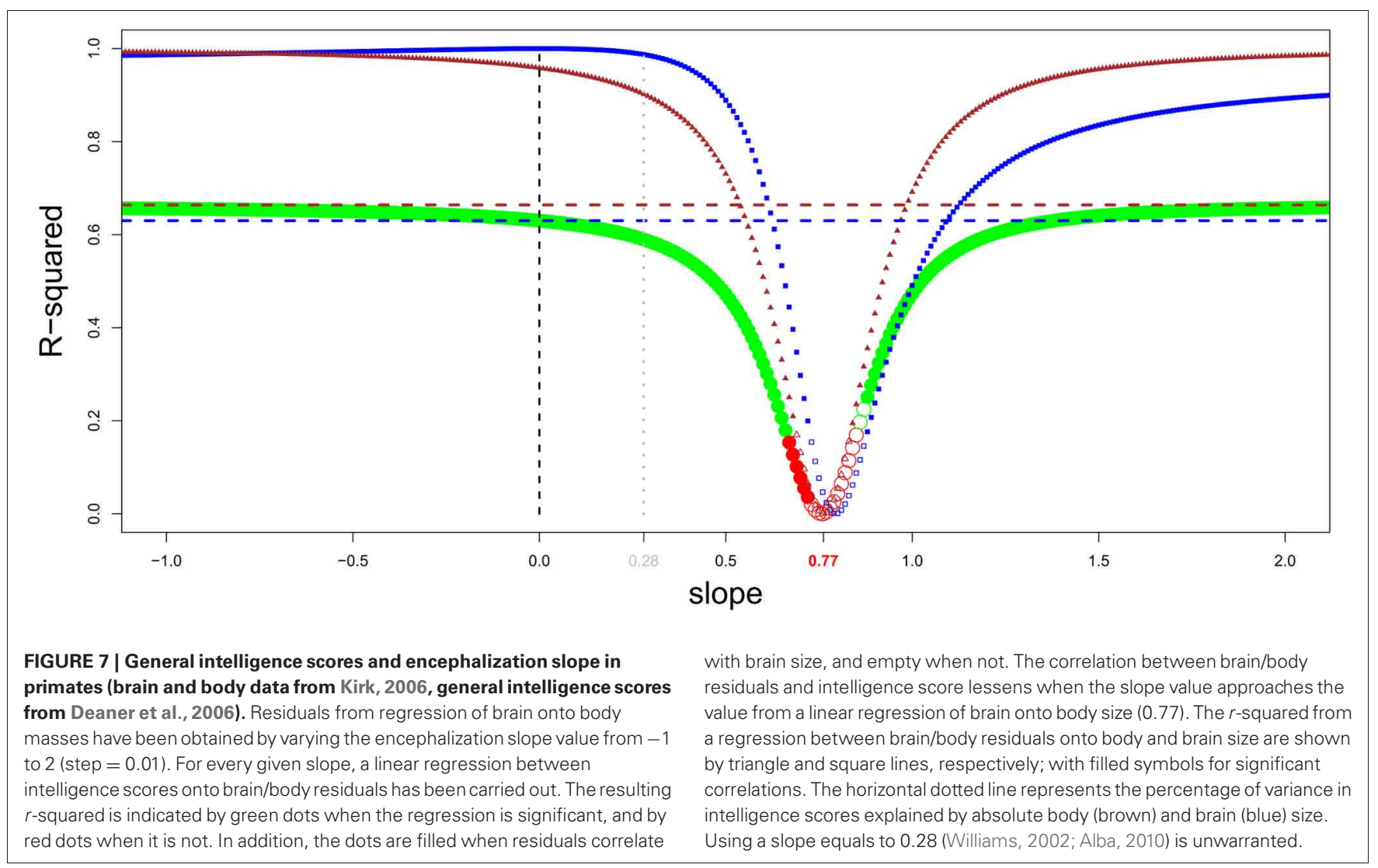

rough approximation of the relationship between the variables that constitute them. As stated by Barton (2012), "the search for a single ideal comparative brain measure that captures the neural basis of cognitive evolution is likely to be more obfuscatory than illuminating, because different selection pressures have acted on different neural systems at different times." Therefore, far from being "fruitless" (Jerison, 1985), looking at finer correlates of cognitive abilities is a fundamental issue in comparative neuroscience.

\section{BRAIN COMPOSITION AND COGNITION}

As pointed out by Striedter (2005) through the example of the small but crucial suprachiasmatic nucleus (that controls circadian rhythms), the importance of a structure in the brain network or in a species' life are two different things. However, absolute features of a brain structure, such as its size and the number of neurons and synapses can theoretically have an impact on the structure's computational power (Striedter, 2005). For example, the particularly sensitive and agile hands of raccoons are linked with a particularly large cortical representation of the forepaws (Welker and Seidenstein, 1959). Importantly, however, whether a bigger structure generates higher processing capacity is true only when the advantages of being larger compensate for the functional constraints on conduction time and neuronal connectivity for example. Therefore, the relation between structure size and processing capacities is not necessarily linear and should depend on the intimate composition of a structure determined by the taxon-cerebrotype characteristics (such as the scaling of cell number in structures, Herculano-Houzel, 2011b). The relative size of brain structure also plays a role in the structure's importance inside the brain network. The principle of "large equals well-connected" (Striedter, 2005 after Deacon, 1990b) states that the larger a structure becomes in evolution, the more its neurons invade the other regions, accenting the region importance in the brain network. It is likely, however, that evolutionary mechanisms (like favoring intrastructure neuronal connection) limit this "invasion" when it is not adaptive.

Because brain structures or regions rarely support only one function, and because apparently similar behaviors can have different underlying cognitive mechanisms, understanding how brain composition influences cognitive abilities is complex. For example, the mechanisms for food hoarding behavior (one of the most studied behavioral traits) vary from simple retrieval mechanisms (Brodin, 2005; Smulders et al., 2010) to probably multi-dimensional maps in which the age and content of the cache is remembered (Clayton and Dickinson, 1998). Moreover, and in addition to the fact that studies often mix various taxa, a number of methodological issues have been highlighted in previous papers (e.g., Bolhuis and Macphail, 2001; Healy and Rowe, 2007; Roth et al., 2010 see also next subpart). Furthermore, the size of a structure is not the only parameter that accounts for its function (Roth et al., 2010), forcing neuroecologists to examine different levels of analysis (Ball et al., 2002; Pollen and Hofmann, 2008). By their correlative nature, comparative analyses are insufficient for studying the mechanisms underlying behaviors so that 
a back and forth paradigm between experimental and comparative analyses is probably needed to study the neuronal correlates of complex behaviors (Pollen and Hofmann, 2008; Smulders et al., 2010) and to eventually draw a evolutionary framework on these characters (MacLean et al., 2012).

\section{METHODOLOGICAL ISSUES}

In addition to the points raised above, three issues in particular affect comparative studies on brain, cognition, and behavior.

(1) The strength of a hypothesis directly depends on the strength of the data on which it is based. Yet, datasets are often too small, making results difficult to interpret. Twenty years ago, Jerison already complained about "how much longer we will have only Stephan and his colleagues for appropriately large samples of measures of the brain" (Jerison, 1993). Except for the contribution of Reep et al. (2007) and some sporadic additions of new mammalian species, the number of species for which brain composition is known has steadied, as have intra-species measurements. This is problematic, since the acuity of the determination of cerebrotype characteristics directly depends on the number of species for which data are available (see also Yopak, 2012). Indeed, while primates are the mammalian order for which there is the largest amount of anatomical and lifestyle data (e.g., Dominy et al., 2004; Striedter, 2005; Preuss, 2007; Barrickman et al., 2008; Herculano-Houzel and Kaas, 2011), data on brain structure is available for less than 25 percent of species (estimated at around 200, Purvis, 1995). Similar conclusions apply to birds, for which high quality data is only available for a limited number of species (Boire and Baron, 1994; Iwaniuk et al., 2004). Fortunately, imaging studies, beside ethical and free from shrinkage problems, can now be used for getting brain measurements (e.g., Semendeferi and Damasio, 2000; Sherwood et al., 2004). After decades of testing, the most complete data on comparative cognition in mammals concerns the primate taxon (Deaner et al., 2006; Reader et al., 2011). However, primate data is incomplete in the number of tests done by each species, requiring complex statistics to compensate for the lack of data (Johnson et al., 2002; Deaner et al., 2006) while still being at the genus level. Data from the wild (e.g., Reader et al., 2011 in primates) represents an important source for mapping species differences in cognitive abilities (Kamil, 1987; Byrne and Bates, 2011). Indeed, ethical methods of data acquisition are developed to test wild or semi-wild animals (e.g., Fagot and Paleressompoulle, 2009; Woods and Hare, 2010; Marino and Frohoff, 2011; Gazes et al., 2013; Healy and Hurly, 2013). Finally, although a few model species in the laboratory have been extensively studied, most of them have been raised for decades in artificially poor environments that potentially affect normal brain functioning (Würbel, 2001 and see section Intra-specific Analyses). Whether it is relative to brain composition or cognitive abilities, increased collaborations, and data sharing are the keys to improving this point (Tomasello and Call, 2011; MacLean et al., 2012).
(2) Because they compare species with shared evolutionary history, comparative studies do not fill the condition necessary for most statistical methods; the independence of data points (Felsenstein, 1985). The use of sophisticated comparative methods (MacLean et al., 2012) associated with high quality phylogenetic trees (e.g., Arnold et al., 2010) is a necessary step to improve our understanding of the evolution of brain, cognition, and behavior.

(3) Whether a correlation is significant or not is only a statistical description of the data, and is insufficient to state that two biological variables co-vary. In other words, $p$-values and regression coefficients are not enough and two questions should systematically be asked in regression analyses. The first is; can the regression predict the value of the variable of interest in a biologically significant way? The second is; can we explain the potential extreme values? Only when these two criteria satisfied are the regression analyses strong enough to serve as basis for other studies. In the other cases, future studies should clarify the relationships between the variables. Importantly, because of the uncertainty existing in variable relationships and the often small datasets available, results from multiple regressions (or related methods) should be interpreted particularly cautiously.

Unless proven otherwise, these issues, and those discussed above, should necessarily have adverse consequences for each paper in which they are found (including some papers reviewed here), so that a number of published works will probably need to be reanalysed as soon as better data is available. Consequently, readers should keep the following biases in mind when referring to previous papers or when designing future research.

\section{SPECIES DIFFERENCES IN COGNITION AND BEHAVIOR COGNITION}

Deacon (1990a) remarked that "no one would consider ranking such mammals as dolphins, rabbits, moles, horses, bats, and gibbons according to some linear scale of locomotor efficiency, capacity, or competence." Similarly, such an observation could be true for cognitive abilities. However, in the case of locomotor efficiency, one can measure species speed or endurance for instance, and this makes sense, for example, when considering prey/predator interaction. Likewise in the case of cognition, one can consider ways to approximate the ability to resolve problems or the ability to have a complex mental representation of the world. Indeed, Andrews (2011), qualifies the current period as "a kind of golden era when it comes to animal cognition research." Considering the number of papers published or the number of subjects tackled, Andrews's observation is certainly right. However, scientists still have a limited understanding about the very nature of cognition and its variation between species. In fact, our understanding of the cognitive capacities of nonhuman and human animals is continuously remodeled by new experiments. Moreover, in a number of papers many species are tested for the presence/absence of cognitive abilities. Such a binary approach can potentially hide quantitative differences between species (Wright, 2010). But maybe the biggest difficulty is that a deep understanding of cognition cannot be achieved without 
taking into account the brain mechanisms underlying it. This is evidently true for detailed analyses at a species level, but it also holds for comparative studies.

For example, Deaner et al. (2006) found that various cognitive measures have strong positive inter-correlations in primates, thereby supporting the hypothesis that "primate taxa differ in some kind of domain-general ability" (see also Reader et al., 2011). However, the presence of such a "general intelligence" factor in primates could be the consequence of the concerted scaling of the brain architecture supporting primates' cognitive abilities (see section Factors Underlying the Evolution of the Size and the Composition of Brains), instead of being an inherent property of cognition. Similarly, Lefebvre and Bolhuis (2003) noted that, in birds, "the negative correlation [between innovation rate and food storing] is consistent with the idea that there has been a trade-off between the demands of storing and innovation" (brackets added), supporting the view of "limited modularity in animal cognition.” However, roughly speaking, if food storing depends closely on the hippocampus and learning and innovation on other nuclei, then the limited modularity of cognitive capacities directly reflects the architecture of the brain (suggesting that different cognitive strategies have been selected). If follows from these two points that understanding the modularity of cognition requires the study of the neurological bases of cognitive abilities. For example, while chimpanzee and bonobo Pan paniscus are phylogenetically very close (Fischer et al., 2011), the significant differences in their behavior (Doran et al., 2002; Hare, 2009) and cognitive abilities (Herrmann et al., 2010) correlate with slight differences in their brain architecture (Rilling et al., 2012, see also Hopkins et al., 2009).

\section{FROM COGNITION TO BEHAVIOR: THE ROLE OF "MENTALITY"}

There are species-specific ways to react to a noise, a conspecific, another species, etc., that go beyond species respective cognitive capacities and that determine, alongside the perceptual abilities proper to each species, what kind of information, through all the information available in the environment, is analysed, and how. Although much less studied than species differences in cognitive capacities, the terms "temperament" (Réale et al., 2007) and "behavioral syndrome" (Sih et al., 2004) have sometimes been proposed to account for this aspect of animal behavior at the individual, population, species, and even group of species levels. This lack of specificity is potentially problematic in a neuroecological approach, since the neurological bases underlying behavioral differences at the species and individual levels possibly differ. For this reason, the term "mentality" has been used here to describe the species-specific way to analyse and react to their environment.

The concept of mentality as defined here encompasses the array of behavioral differences that are not directly due to species differences in cognitive abilities; such as patience (Stevens et al., 2005; Rosati et al., 2007; Addessi et al., 2011; Pelé et al., 2011) and inhibitory control (Amici et al., 2008), differences in risk preference (Heilbronner et al., 2008), neophilia and exploration (Parker, 1974; Mettke-Hofmann et al., 2002, 2005; Bergman and Kitchen, 2009) among others. Such differences between species could result from large or small changes in the pattern of brain structure (e.g., Rilling et al., 2012) or neuropeptides (e.g., Young, 1999; Lim et al., 2004; Goodson and Kingsbury, 2011) for example, controlling how species collect and process information about their environment (see also Lotem and Halpern, 2012). Because of the homogeneity of brains inside a taxoncerebrotype, species generally act in a closer way than compared to species from other taxon-cerebrotypes. Although this issue has still to be studied thoroughly (see for example Auersperg et al., 2012), mentality differences between species could have profound effects on species apparent cognitive abilities (e.g., Greenberg and Mettke-Hofmann, 2001; Greenberg, 2003; Hare, 2009; Byrne and Bates, 2010). Indeed, (Amici et al., 2012) found that in seven primate species, performances in several cognitive tasks correlate with certain properties of their social system for which mentality plays an important role. Mapping species differences in mentality along with differences in cognitive abilities is therefore necessary to understand species differences in behavior.

\section{INTRA-SPECIFIC ANALYSES BRAIN/BODY AND BRAIN STRUCTURES SCALING}

Some individual minks Mustela vison, have brains up to $40 \%$ larger than others [mean brain around $9 \mathrm{~g}$, data from Kruska (1996)]. Likewise, differences between the smallest and largest brains reaches $800 \mathrm{~g}$ in humans (mean brain around $1300 \mathrm{~g}$, Holloway, 1980) and more than $2000 \mathrm{~g}$ in elephants Loxodonta africana (mean brain size roughly equal to $5000 \mathrm{~g}$, Shoshani et al., 2006). Because large individuals need larger organs, muscles or bones, it could be expected that a part of the variance in brain size is explained by body size. In minks for example, there is a strong correlation between individual brain and body sizes [cor $=0.97$, data from Kruska (1996) range body weight: 510-1272 g]. However, in other species such as primates species (see Figure 8, see also Heymsfield et al., 2012) and at least some bird species (e.g., Møller, 2010) the relationship between brain and body mass is weak or absent. In fact, how body size influences brain size inside a species is unknown and has still to be examined with a large and systematic comparative dataset (see also Holloway, 1980). Species with important sexual dimorphism, such as pinnipeds (Bininda-Emonds, 2000; Fitzpatrick et al., 2012) would be particularly interesting (see also Falk et al., 1999). Also, the process of domestication (Belyaev, 1979; Price, 1999; Trut et al., 2009) is of particular interest here, because of the variability between brain and body size among different breeds [review by Kruska (2005)]. Such studies could ultimately clarify the degree to which body size variations influence brain size (for example via constraints on skull size, e.g., Morriss-Kay and Wilkie, 2005). There has been intense debate concerning whether body size should be accounted for when considering brain size differences between human groups (Peters et al., 1998) or during evolutionary history of the human species (e.g., Pilbeam and Gould, 1974). Ultimately, such issues should be studied by analysing inter-individual variation in brain structure sizes.

Finlay et al. (2011) have studied the inter-individual variations of brain structure sizes in minks, pigs, and laboratory mice, and concluded that "the pattern of individual variation in 

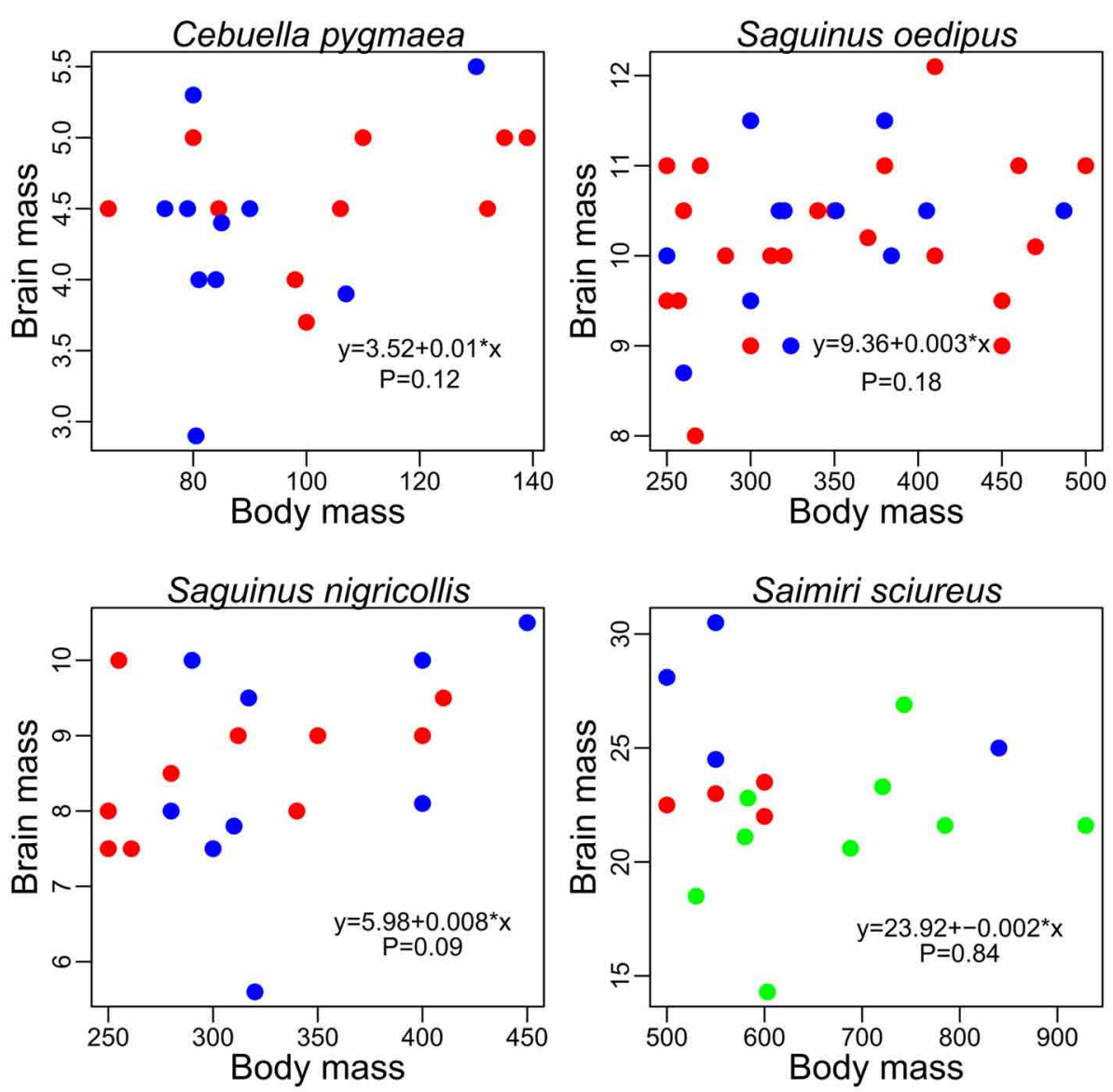

FIGURE 8 | Brain and body mass (grams) in pygmy marmoset (Cebuella pygmaea) two species of tamarin (Saguinus nigricollis and Saguinus oedipus) and in squirrel monkeys (Saimiri sciureus), data from Hartwig et al. (2011). Females, red; males, blue; unknown sex, green.

brain component structure $[. .$.$] is very similar to variation across$ species in the same components, at a reduced scale." Although the inclusion of domestic individuals is potentially problematic (see below), this hypothesis is apparently supported by a study using brain data from 90 young adult humans (Charvet et al., 2013) which suggests that the same (developmental) mechanisms could be responsible for both within and between species variations in brain anatomy. As stated in sections Comparative Brain Studies in Birds and Mammals and Comparing Taxon and Species Cerebrotypes, the patterns of brain variation at the mammal level to which these studies refer to are relatively uninformative (see also Willemet, 2012). Since the range of variation between human brains is larger than the range of variation in all the simian species altogether, such a large dataset is particularly interesting for understanding the intra-species variation of brain composition. Indeed, a principal component analysis on brain structure proportion shows that the pattern of variation of human brain composition seems in continuity with the pattern of variation of simian brain composition (Figure 9A).

The resemblance could be superficial, however. In particular, a large part of this result (and of those of Charvet et al., 2013) could be due to the phenomenon described in section Relative Brain Size; large size differences between human brains are likely to be due to differences in the biggest structures: the neocortex and to a lesser degree, the cerebellum; thereby resembling species variation across species. Indeed, repeating the analysis on simulated brains shows a similar pattern (Figure 9B). Furthermore, the hyperscaling found for primate frontal cortex (Bush and Allman, 2004) is not found in the human sample. In fact, it seems that there is no predictable variation of cortical composition in human (Figure 10).

These results suggest that the mechanisms underlying interindividual variations in brain structure sizes might be different from those having been selected at the species level. Understanding the genetic basis of some particular brain conformation and in particular in humans, in microcephaly (e.g., Mahmood et al., 2011) and rare developmental disease (e.g., Manzini and Walsh, 2011; Netchine et al., 2011), could probably shed light on some of the mechanisms controlling brain size and composition inside a species (and to some extent between species, e.g., Gilbert et al., 2005; Molnár et al., 2006). Also interesting are the seasonal variations of brain structure sizes in some birds and mammals (Yaskin, 1994; Jacobs, 1996; Tramontin 


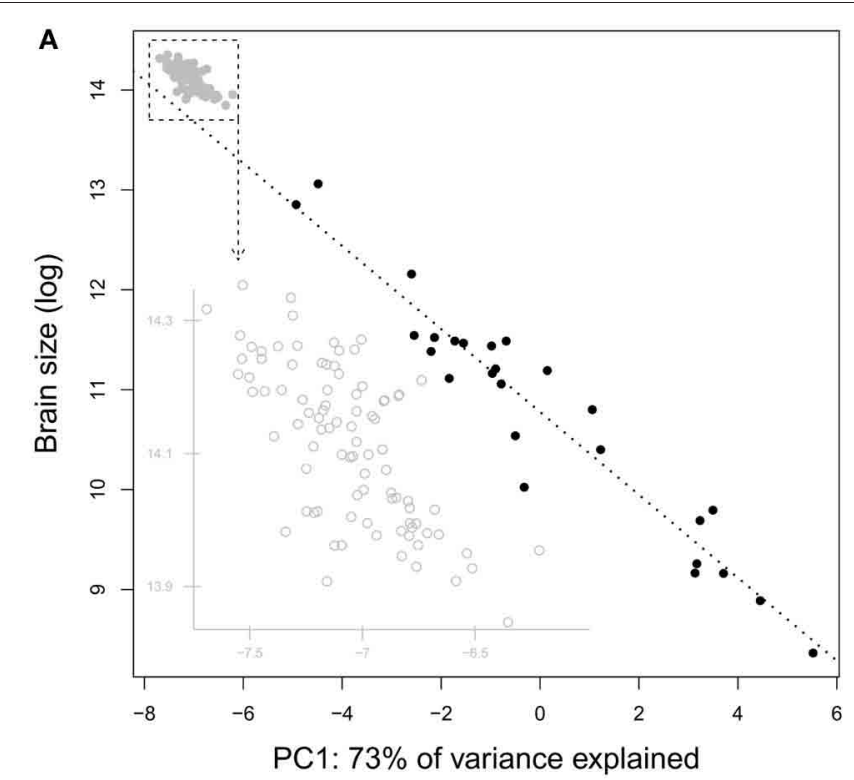

FIGURE 9 | (A) Brain size as a function of the species position on the first component of a principal component analysis of simians' brain structure proportions (the structures included are medulla, cerebellum, mesencephalon, diencephalon, striatum, septum, olfactory cortex, hippocampus, subicular cortex, neocortex). The position of the human individuals (gray) has been predicted by the PCA done with simian species

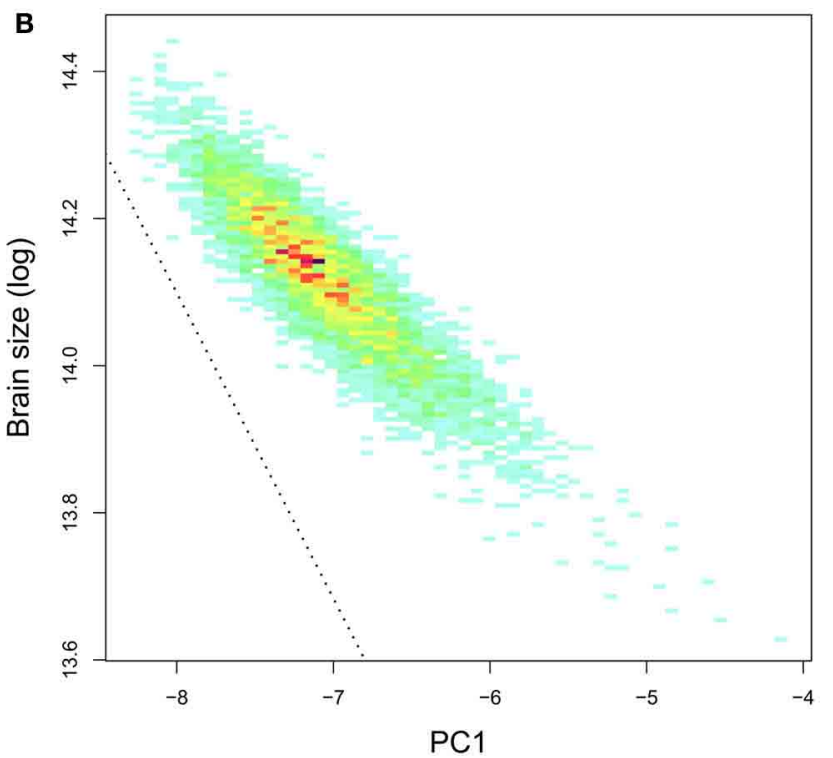

(human species excluded). (B) Density plot based on the position on the precedent first component of 5000 simulated brains constructed by taking 5000 random values for every structure with a normal distribution and a mean and standard deviation similar to the real dataset. The dashed line indicates the regression slope for simian brain size as a function of species position on the principal component analysis.

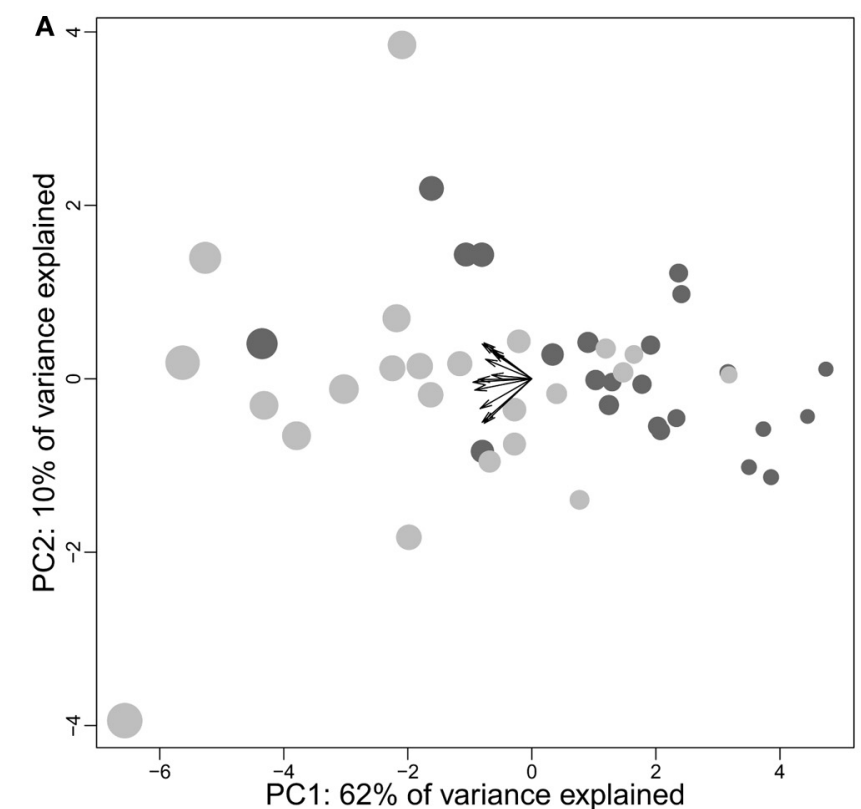

FIGURE 10 | Principal component analyses of cortex subparts in humans using absolute sizes (A) and structure proportions (B). Data come from Allen et al. (2002) and consist in the volumes of 12 cortical regions (frontal, temporal, parietal, occipital, cingulate, insula on both hemispheres). Females, dark gray; males, light gray. (A) Correlation

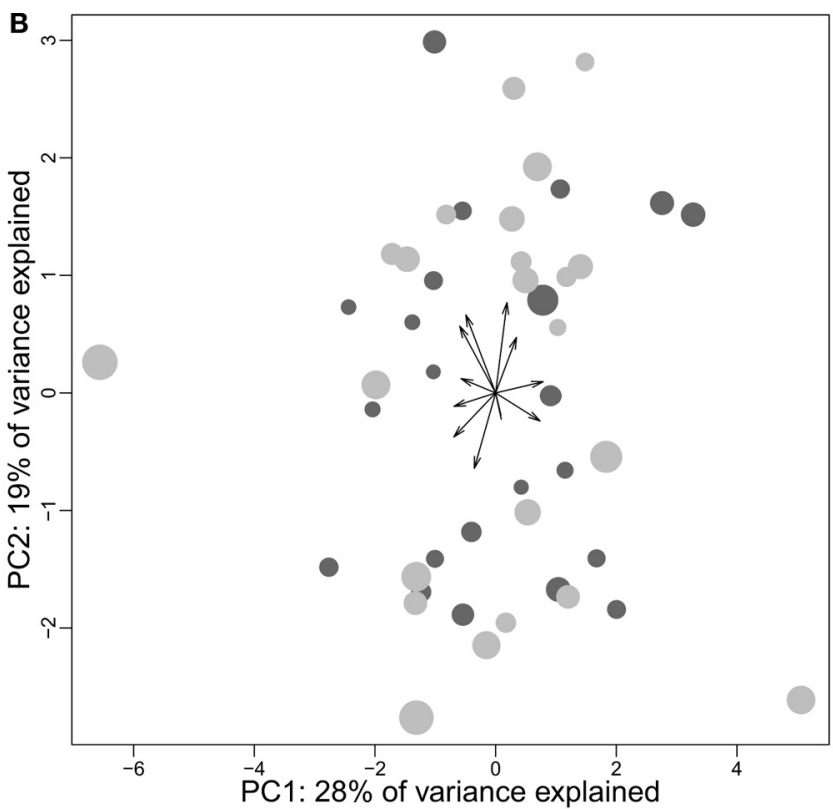

between neocortex size and position on PC1: cor $=-0.99, t=-42.3528$, $d f=44, p$-value $<2.2 \mathrm{e}-16$; (B) Correlation between neocortex size and position on PC1: cor $=-0.02, t=-0.165, d f=44, p$-value $=0.8697$. The arrows represent the structure loadings on the two firsts principal components. 
and Brenowitz, 2000; Sherry and Hoshooley, 2010). Evo-devo researchers have already described some of the mechanisms that have been selected during brain evolution [review in Charvet and Striedter (2011), see also Lipp and Wolfer (2002) and Katz (2011) for discussion on the evolution of complex nervous system]. Accordingly, it has been shown that the size of brain structures is heritable (Airey et al., 2000; Thompson et al., 2002; Fears et al., 2009) and controlled by independent loci (Hager et al., 2012). In controlled conditions, selection for a particular behavior (high voluntary wheel running) has been associated with larger midbrains in domestic mice (Kolb et al., 2013). Interestingly, sex-differences in brain architecture in primate species suggest that female and male brains could be under different sets of selection pressures (Lindenfors et al., 2007; Smaers et al., 2012b). For this reason, sex should be accounted for in studies on the selection pressures underlying the evolution of the brain.

Domestication represents a particularly valuable resource for understanding how brain structures can be selected at the species level (see Kruska, 2005 for a review and Gleich et al., 2000 and Rehkämper et al., 2003, 2008 for recent contributions). What emerged from this body of work are profound differences in brain composition between domesticated and wild forms [review in Kruska $(1988,2005,2007)]$. However, the number of individuals per species and per condition (wild vs. domestic) is often very small (typically less than 4-6). Moreover, the method used in most studies [detailed in Ebinger (1974)] confounds the effect of brain reduction (or body size augmentation) as well as absolute and relative changes in structure volume. This makes the results difficult to interpret. For example, while mean neocortex size is larger in ranch individuals than in wild minks (4802 vs. $4622 \mathrm{~mm}^{3}$ ), this method gives a $17.8 \%$ reduction of neocortex size from wild to ranch minks (Kruska, 1996). In spite of this, reiterating the analyses with a different method supports one of the original conclusions that in most species, the neocortex is the structure most affected by domestication (Finlay et al., 2011). Although the reasons for such changes are unknown, this suggests that some functions supported by the neocortex may have become unnecessary during domestication, or that some mechanisms permitting a decrease in brain structure size while preserving (at least some of) the functions have come along with domestication. In fact, is is possible that most of the neurological differences between domestic and wild individuals are to be found in factors other than size (e.g., Saetre et al., 2004).

\section{INTER-INDIVIDUAL DIFFERENCES IN COGNITION}

In humans, where most studies have been conducted, both the genetic bases (Frank and Fossella, 2011; Green et al., 2012 but see Deary et al., 2009; Chabris et al., 2012) and neuroanatomical correlates of individual differences in cognitive abilities are still unclear. A significant amount of evidence suggests that in humans, the scores obtained in different cognitive tests correlate with each other, so that a global factor, called " $g$ " for general intelligence, accounts for an important part of total variance (at least 40 percent, Deary et al., 2010). This suggests that cognitive abilities are not totally independent of each other, sharing (at least partly) a common mechanism (e.g., Ebisch et al., 2012 but see also Rabaglia et al., 2011). In fact, more and more evidence indicates that general cognitive abilities originate from a network of interconnected cortical areas (Deary et al., 2010). Indeed, it seems that intelligence correlates with brain size in humans (correlation around 0.3 McDaniel, 2005, but see Schoenemann et al., 2000). Absolute features such as the degree of girification (e.g., Germanaud et al., 2012) or neuron number (at least in the neocortex; Pakkenberg and Gundersen, 1997) could probably explain a part of this relationship. However, whether inter-individual variations in structure size and neuron number always correlate has still to be studied thoroughly (in the number of species, individual per species, and structures). For example, in 9 owl monkeys individuals Aotus trivirgatus, Collins et al. (2013) have found no significant correlation between the masses of several visual brain structures and neuron number. Inter-individual differences in cognitive abilities go beyond such a general factor. Indeed, human studies have shown that for every cognitive test, part of the unexplained variance "reflects the particular abilities involved in the test" (Deary et al., 2010). More exactly, particular cognitive abilities seem to be supported by localized brain areas (e.g., Johnson et al., 2008, see also Gläscher et al., 2010). While the understanding of the neurological bases of individual differences in cognitive abilities is still in its infancy, it is complicated by the role of environment in both brain composition and cognitive abilities (Mohammed et al., 2002; Simpson and Kelly, 2011), and by individual differences in perceptual abilities (Kanai and Rees, 2011).

The considerable work in humans contrasts with the small literature on this subject in other species, where individual differences in cognitive abilities have often been considered as variation around a mean (Thornton and Lukas, 2012). Yet, a similar "g factor" has been found in the other species investigated [review by Chabris (2007), see also Banerjee et al. (2009) on cotton-top tamarin Saguinus Oedipus and Matzel et al. (2011) on mice, but see Vonk and Povinelli (2011) and Herrmann and Call (2012) for mixed results in chimpanzees and apes, respectively]. In addition, it has been proposed that cognitive capacities correlate with brain size in rats (Anderson, 1993). In fact, although there is a growing body of research on the evolutionary significance of individual variation in cognitive abilities (Boogert et al., 2011; Cole et al., 2012; Thornton and Lukas, 2012; Cauchard et al., 2013), individual differences in cognitive abilities have still to be systematically investigated in non-human animals.

Interestingly, the mechanisms underlying species differences in cognitive abilities probably differ from those between individuals of a species. Firstly, as described above, variations of processing capacities inside a taxon cerebrotype is probably due to the cumulative effect of brain structure scaling and absolute features that go along with larger brains. Between individuals of a species, however, such kind of brain structure scaling is apparently limited (for example in the absence of hyperscaling of frontal cortex, see above). Secondly, while brain size correlates both with reaction time and general intelligence in human [see review by Chabris (2007)] macaque monkeys are faster than humans on certain visual tasks, for a degree of accuracy quite similar (Vauclair et al., 1993; Fabre-Thorpe et al., 1998; Delorme et al., 2000; Fize et al., 
2011). If such a trend was confirmed with a systematic analysis (see also Washburn and Rumbaugh, 1997), this would suggest that brain size variations have different meanings given the level of variation; individuals or species. Therefore, hypotheses on the factors underlying inter and intra-species differences in cognitive abilities should be carefully examined before, maybe, being transferred between these two levels.

\section{INTER-INDIVIDUAL DIFFERENCES IN PERSONALITY}

The concept of "personality" describes the behavioral differences between individuals of a species that go beyond their respective differences in cognitive abilities (see Gosling, 2001, and Uher, 2011 for a review of the term used). Individual differences in "personality" can now be identified in "in a broad array of species, ranging from squid, crickets, and lizards, to trout, geese, and orangutans" (Gosling, 2008; see also Weiss et al., 2012). It is likely, however, that the neuronal mechanisms underlying individual characteristics among guppies differ from those between rats for example. Indeed, and although the differences between the two may have been overstated (Shiner and DeYoung, 2013), the traditional distinction between temperament and personality (where, schematically, temperament describes biologically anchored behavioral traits while personality includes the effects of individual construction through personal history) used in human research could be of interest here (see also Stamps and Groothuis, 2010).

Insight will come by studying the mechanisms underlying inter-individual differences in personality (Robinson, 2001; Buckholtz et al., 2007; Blatchley and Hopkins, 2010; Adelstein et al., 2011) and their genetic bases (Plomin, 1990; Fidler et al., 2007; Adams, 2011). The fact that personality traits can be linked with differences in brain anatomy (e.g., DeYoung et al., 2010) poses the question of whether personality affects brain composition, or whether brain composition affects personality. It is likely, in fact, that these two levels interact. Domestication could be particularly interesting here (Trut, 1999; Agnvall et al., 2012; Kukekova et al., 2012). As more species are studied, inter-species differences in personality structures (that is, the dimensions particular to each species onto which individual differences take place, Uher and Asendorpf, 2008) will be mapped. This is important since personality traits affect individual life-history traits (Biro and Stamps, 2008), therefore having an important role in the fitness of an individual (Dingemanse et al., 2004; Smith and Blumstein, 2008; Réale et al., 2007, 2010; Wolf et al., 2007; Schuett et al., 2010; Wolf and Weissing, 2010). In the same way that cognitive abilities cannot be studied between species without the mentality concept described earlier, inter individual differences in cognitive abilities and personality must be studied conjointly for understanding individual differences in behavior (Locurto, 2007; Carere and Locurto, 2011; Sih and Del Giudice, 2012). Both levels have been central in species evolution.

\section{CONCLUDING REMARKS}

Beside all the methodological and conceptual problems reported here, a significant bias in evolutionary neuroscience is the particular place given to human brain and cognition. As stated by Deacon; "we are, after all, the 'sapient' ape, distinguished from all other species by our unusual mental powers. But this has also motivated the many preconceptions that we bring to the topic that affect both the selection of scientific evidence and our interpretations of it. The single most pervasive issue behind most of these preconceptions is the notion of human intellectual superiority" (Deacon, 1990a, original quotation marks). Under this view, it is the fact that the human brain is not at the top of a criterion that makes this criterion inadequate for determining intelligence, and conversely. The misconceptions that this approach has lead, even at the brain size level (see above), have a heuristic value and warn against considering this approach for more complex variables. This comment echoes Chittka et al. (2012) who, referring to an analysis that found human species to be the slowest in a color learning task, warned that although "there may be good reasons not to equate learning speed with intelligence [...] the fact that humans do not top the chart should not be one of them."

The importance of such fallacies can be broadened to the mammalian brain in general. For instance, spontaneous mirror self-recognition occurs with the $350 \mathrm{~g}$ chimpanzee's brain (Gallup, 1970), the $2000 \mathrm{~g}$ dolphin brain Tursiops truncatus (Reiss and Marino, 2001) and the $4000 \mathrm{~g}$ elephant brain Elephas maximus (Plotnik et al., 2006) but also with the small $5 \mathrm{~g}$ magpie brain Pica pica (Prior et al., 2008). More generally, the complex cognitive abilities of several bird species (Emery and Clayton, 2004; Emery, 2006; Kirsch et al., 2008), suggest that the brain architecture of birds is particularly efficient. This is interesting, given the relatively recent misconception that bird intelligence was limited and their behaviors only stereotyped (Emery, 2006) and the still widely accepted postulate that the mammalian brain is the most complex and efficient structure in term of cognitive abilities. In fact, the highest ratio of cognitive abilities to neuron number could possibly be found in non-vertebrate taxa such as cephalopods (e.g., Hochner et al., 2006; Grasso and Basil, 2009; Ikeda, 2009) and insects (e.g., Menzel and Giurfa, 2001; Chittka and Skorupski, 2011).

Finally, it is particularly striking to note [as Griffin (1976) did more than twenty-five years ago] that the subjective part of behavior, that is, the way animals experience the world, has been systematically put aside in comparative studies of animal behavior. As stated by Shettleworth (2001): "it is possible, indeed usual, to study the ways in which animals acquire information about the world through their senses, process, retain and respond to it without making any commitment about the nature of their subjective experience or awareness." Yet, what makes a bird or mammal flee danger is fear or pain, to search for food is hunger, what makes it look for mates is sexual arousal and for a place to sleep is fatigue, so that the subjective dimension of animal mind; consciousness, is the fundamental link between brain, cognition, and behavior. Studying animal brain and behavior without raising the question of how animals experience the world is likely to be as incomplete as was studying biology without evolution. In fact, this is one of evolutionary neuroscience's principal challenges.

\section{ACKNOWLEDGMENTS}

Three reviewers made useful comments on a previous version of this paper. 


\section{REFERENCES}

Aboitiz, F. (1996). Does bigger mean better? Evolutionary determinants of brain size and structure. Brain Behav. Evol. 47, 236-245. doi: $10.1159 / 000316275$

Aboitiz, F. (2001). What determines evolutionary brain growth? Behav. Brain Sci. 24, 278-279.

Adams, M. J. (2011). "Evolutionary genetics of personality in nonhuman primates," in From Genes to Animal Behavior: Social Structures, Personality, Communication by Colors, eds M. Inoue-Murayama, A. Weiss, and S. Kawamura (Tokyo: Springer), 137-164.

Addessi, E., Paglieri, F., and Focaroli, V. (2011). The ecological rationality of delay tolerance: insights from capuchin monkeys. Cognition 119, 142-147. doi: 10.1016/j.cognition.2010.10.021

Adelstein, J. S., Shehzad, Z., Mennes, M., DeYoung, C. G., Zuo, X. N., Kelly, C., et al. (2011). Personality is reflected in the brain's intrinsic functional architecture. PLoS ONE 6:e27633. doi: 10.1371/journal.pone.0027633

Agnvall, B., Jöngren, M., Strandberg, E. and Jensen, P. (2012). Heritability and genetic correlations of fearrelated behaviour in red Junglefowl - possible implications for early domestication. PLoS ONE 7:e35162. doi:10.1371/journal.pone.0035162

Aiello, L. C., and Wheeler, P. (1995). The expensive-tissue hypothesis: the brain and the digestive system in human and primate evolution. Curr. Anthropol. 36, 199-221. doi: $10.1086 / 204350$

Airey, D. C., Castillo-Juarez, H., Casella, G., Pollak, E. J., and DeVoogd, T. J. (2000). Variation in the volume of zebra finch song control nuclei is heritable: developmental and evolutionary implications. Proc. R. Soc. B Biol. Sci. 267, 2099-2104.

Alba, D. M. (2010). Cognitive inferences in fossil apes (Primates, Hominoidea): does encephalization reflect intelligence. J. Anthropol. Sci. $88,11-48$.

Allen, J. S., Damasio, H., and Grabowski, T. J. (2002). Normal neuroanatomical variation in the human brain: an MRI-volumetric study. Am. J. Phys. Anthropol. 118, 341-358. doi: 10.1002/ajpa.10092

Allman, J., McLaughlin, T., and Hakeem, A. (1993). Brain weight and life-span in primate species. Proc. Natl. Acad. Sci. U.S.A. 90, 118-122. doi: 10.1073/pnas.90.1.118

Amici, F., Aureli, F., and Call, J. (2008). Fission-fusion dynamics, behavioral flexibility, and inhibitory control in primates. Curr. Biol. 18, 1415-1419. doi: 10.1016/j.cub.2008.08.020

Amici, F., Aureli, F., and Call, J. (2010). Monkeys and apes: are their cognitive skills really so different? Am. J. Phys. Anthropol. 143, 188-197.

Amici, F., Barney, B., Johnson, V. E., Call, J., and Aureli, F. (2012). A modular mind? A test using individual data from seven primate species. PLoS ONE 7:e51918. doi: 10.1371/journal.pone.0051918

Anderson, B. (1993). Evidence from the rat for a general factor that underlies cognitive performance and that relates to brain size: intelligence? Neurosci. Lett. 153, 98-102.

Anderson, M. L. (2010). Neural reuse: a fundamental organizational principle of the brain Behav. Brain Sci. 33, 245-266. doi: 10.1017/S0140525X10000853

Andrews, K. (2011). "Animal cognition," in The Stanford Encyclopedia of Philosophy (Summer 2011 Edition). Available online at: http:// plato.stanford.edu/entries/cognition animal/

Arnold, C., Matthews, L. J., and Nunn, C. L. (2010). The 10kTrees website: a new online resource for primate phylogeny. Evol. Anthropol. 19, 114-118. doi: 10.1002/evan.20251

Auersperg, A. M. I., Gajdon, G. K., and von Bayern, A. M. P. (2012). A new approach to comparing problem solving, flexibility and innovation. Commun. Integr. Biol. 5, 140-145. doi: 10.4161/cib.18787

Ball, G. F., Riters, L. V., and Balthazart, J. (2002). Neuroendocrinology of song behavior and avian brain plasticity: multiple sites of action of sex steroid hormones. Front. Neuroendocrinol. 23, 137-178. doi: 10.1006/frne.2002.0230

Balsters, J. H., Cussans, E., Diedrichsen, J., Phillips, K. A., Preuss, T. M., Rilling, J. K., et al. (2010). Evolution of the cerebellar cortex: the selective expansion of prefrontalprojecting cerebellar lobules. Neuroimage 49, 2045-2052. doi: 10.1016/j.neuroimage.2009.10.045

Banerjee, K., Chabris, C. F., Johnson, V. E., Lee, J. J., Tsao, F., and Hauser, M. D. (2009). General intelligence in another primate: individual differences across cognitive task performance in a New World monkey (Saguinus oedipus). PLoS ONE 4:e5883. doi: 10.1371/journal.pone.0005883

Barrett, L. (2011). Beyond the Brain : How Body and Environment Shape Animal and Human Mind. New
Jersey, NJ: Princeton University Press.

Barrickman, N. L., Bastian, M. L. Isler, K., and van Schaik, C. P. (2008). Life history costs and benefits of encephalization: a comparative test using data from longterm studies of primates in the wild. J. Hum. Evol. 54, 568-590. doi 10.1016/j.jhevol.2007.08.012

Barton, R. A. (1998). Visual specialization and brain evolution in primates. Proc. Roy. Soc. B Biol. Sci. 265, 1933-1937. doi: 10.1098/rspb.1998.0523

Barton, R. A. (2002). How did brains evolve? Nature 415, 134-135.

Barton, R. A. (2004). Binocularity and brain evolution in primates. Proc. Natl. Acad. Sci. U.S.A. 101, 10113-10115. doi: $10.1073 /$ pnas.0401955101

Barton, R. A. (2007). Evolutionary specialization in mammalian cortical structure. J. Evol. Biol. 20, 1504-1511. doi: 10.1111/j.1420-9101.2007.01330.x

Barton, R. A. (2012). Embodied cognitive evolution and the cerebellum. Philos. Trans. Roy. Soc B Biol. Sci. 367, 2097-2107. doi: 10.1098/rstb.2012.0112

Barton, R. A., and Capellini, I. (2011) Maternal investment, life histories, and the costs of brain growth in mammals. Proc. Natl. Acad. Sci. U.S.A. 108, 6169-6174. doi: 10.1073/pnas.1019140108

Barton, R. A., and Harvey, P. H. (2000). Mosaic evolution of brain structure in mammals. Nature 405 1055-1057. doi: 10.1038/35016580

Belyaev, D. K. (1979). Destabilizing selection as a factor in domestication. J. Heredity 70, 301-308.

Bergman, T. J., and Kitchen, D. M. (2009). Comparing responses to novel objects in wild baboons (Papio ursinus) and geladas (Theropithecus gelada). Anim. Cogn 12, 63-73. doi: 10.1007/s10071-0080171-2

Bininda-Emonds, O. R. P. (2000). Pinniped brain sizes. Mar. Mamm. Sci. 16, 469-481. doi: 10.1111/j.17487692.2000.tb00939.x

Biro, P. A., and Stamps, J. A. (2008). Are animal personality traits linked to life-history productivity? Trends Ecol. Evol. 23, 361-368.

Blatchley, B. J., and Hopkins, W. D. (2010). Subgenual cingulate cortex and personality in chimpanzees (Pan troglodytes). Cogn. Affect. Behav. Neurosci. 10, 414-421. doi: 10.3758/CABN.10.3.414

Boire, D., and Baron, G. (1994). Allometric comparison of brain and main brain subdivisions in birds J. Brain Res. 35, 49-66.

Bolhuis, J. J., and Macphail, E. M. (2001). A critique of the neuroecology of learning and memory. Trends Cogn. Sci. 5, 426-433. doi: $\quad 10.1016 / S 1364-6613(00)$ 01753-8

Boogert, N. J., Fawcett, T. W., and Lefebvre, L. (2011). Mate choice for cognitive traits: a review of the evidence in nonhuman vertebrates. Behav. Ecol. 22, 447-459. doi: 10.1093/beheco/arq173

Brodin, A. (2005). Mechanisms of cache retrieval in long-term hoarding birds. J. Ethol. 23, 77-83. doi 10.1007/s10164-005-0147-5

Brunet-Rossinni, A. K., and Austad, S. N. (2004). Ageing studies on bats: a review. Biogerontology 5, 211-222. doi: 10.1023/ B:BGEN.0000038022.65024.d8

Buckholtz, J. W., Callicott, J. H. Kolachana, B., Hariri, A. R., Goldberg, T. E., Genderson, M. et al. (2007). Genetic variation in MAOA modulates ventromedial prefrontal circuitry mediating individual differences in human personality. Mol. Psychiatry 13, 313-324. doi: 10.1038/sj.mp.4002020

Burish, M. J., Peebles, J. K., Baldwin, M. K., Tavares, L., Kaas, J. H., and Herculano-Houzel, S. (2010). Cellular scaling rules for primate spinal cords. Brain Behav. Evol. 76, 45-59. doi: 10.1159/000319019

Bush, E. C., and Allman, J. M. (2004). The scaling of frontal cortex in primates and carnivores. Proc. Natl. Acad. Sci. U.S.A. 101, 3962-3966. doi: 10.1073/pnas.0305760101

Butler, A. B., and Hodos, W. (2005). Comparative Vertebrate Neuroanatomy: Evolution and Adaptation. New York, NY: Wiley-Liss. doi: 10.1002/047173 3849

Butti, C., Raghanti, M. A., Sherwood, C. C., and Hof, P. R. (2011). The neocortex of cetaceans: cytoarchitecture and comparison with other aquatic and terrestrial species. Ann. N.Y. Acad. Sci. 1225, 47-58. doi: 10.1111/j.1749-6632.2011.05980.x

Byrne, R. W. (1997). “The technical intelligence hypothesis: an additional evolutionary stimulus to intelligence?" in Machiavellian Intelligence II: Extensions and Evaluations, eds A. Whiten and R. W. Byrne (Cambridge: Cambridge University Press), 289-311.

Byrne, R. W., and Bates, L. A. (2010). Primate social cognition: uniquely primate, uniquely social, or just unique? Neuron 65, 815-830. 
Byrne, R. W., and Bates, L. A. (2011). Cognition in the wild: exploring animal minds with observational evidence. Biol. Lett. 7, 619-622. doi: 10.1098/rsbl.2011.0352

Byrne, R. W., and Whiten, A. (1989). Machiavellian Intelligence: Social Expertise and the Evolution of Intellect in Monkeys, Apes, and Humans. Oxford: Oxford University Press.

Cahalane, D. J., Charvet, C. J., and Finlay, B. L. (2012). Systematic, balancing gradients in neuron density and number across the primate isocortex. Front. Neuroanat. 6:28. doi: 10.3389/fnana.2012.00028

Carere, C., and Locurto, C. (2011). Interaction between animal personality and animal cognition. Curr. Zool. 57, 491-498.

Cauchard, L., Boogert, N. J., Lefebvre, L., Dubois, F., and Doligez, B. (2013). Problem-solving performance is correlated with reproductive success in a wild bird population. Anim. Behav. 85, 19-26. doi: 10.1016/j.anbehav.2012.10.005

Chabris, C. F. (2007). "Cognitive and neurobiological mechanisms of the Law of General Intelligence," in Integating the Mind, ed M. J. Roberts (Hove: Psychology Press), 449-491.

Chabris, C. F., Hebert, B. M., Benjamin, D. J., Beauchamp, J., Cesarini, D., van der Loos, M., et al. (2012). Most reported genetic associations with general intelligence are probably false positives. Psychol. Sci. 23, 1314-1323. doi: 10.1177/095679 7611435528

Changizi, M. A. (2010). Neuroscientist's embarrassment: artificial intelligence's opportunity. Brain Behav. Evol. 75, 85. doi: 10.1159/000306447

Changizi, M. A., and Shimojo, S. (2005). Parcellation and area-area connectivity as a function of neocortex size. Brain Behav. Evol. 66, 88-98. doi: 10.1159/000085942

Charvet, C. J., Darlington, R. B., and Finlay, B. L. (2013). Variation in human brains may facilitate evolutionary change toward a limited range of phenotypes. Brain Behav. Evol. 81, 74-85. doi: 10.1159/000345940

Charvet, C. J., and Finlay, B. L. (2012). Embracing covariation in brain evolution: large brains, extended development, and flexible primate social systems. Prog. Brain Res. 195, 71-87. doi: 10.1016/B978-0-44453860-4.00004-0

Charvet, C. J., and Striedter, G. F. (2011). Developmental modes and developmental mechanisms can channel brain evolution.
Front. Neuroanat. 5:4. doi: 10.3389/fnana.2011.00004

Chittka, L., and Niven, J. (2009). Are bigger brains better? Curr. Biol. 19, 995-1008.

Chittka, L., Rossiter, S. J., Skorupski, P., and Fernando, C. (2012). What is comparable in comparative cognition? Philos. Trans. Roy. Soc. B Biol. Sci. 367, 2677-2685.

Chittka, L., and Skorupski, P. (2011). Information processing in miniature brains. Proc. Roy. Soc. B Biol. Sci. 278, 885-888. doi: 10.1098/rspb.2010.2699

Clark, D. A., Mitra, P. P., and Wang, S. S. H. (2001). Scalable architecture in mammalian brains. Nature 411, 189-192. doi: 10.1038/35075564

Clayton, N. S., and Dickinson, A. (1998). Episodic-like memory during cache recovery by scrub jays. Nature 395, 272-273. doi: $10.1038 / 26216$

Clutton-Brock, T., and Harvey, P. H. (1980). Primates, brains and ecology. J. Zool. 190, 309-323. doi: 10.1111/j.14697998.1980.tb01430.x

Cole, E. F., Morand-Ferron, J., Hinks, A. E., and Quinn, J. L. (2012). Cognitive ability influences reproductive life history variation in the wild. Curr. Biol. 22, 1808-1812. doi: 10.1016/j.cub.2012.07.051

Collins, C. E., Leitch, D. B., Wong, P., Kaas, J. H., and HerculanoHouzel, S. (2013). Faster scaling of visual neurons in cortical areas relative to subcortical structures in non-human primate brains. Brain Struct. Funct. 218, 805-816. doi: 10.1007/s00429-0120430-5.

Deacon, T. W. (1990a). Fallacies of progression in theories of brainsize evolution. Int. J. Primatol. 11, 193-236.

Deacon, T. W. (1990b). Rethinking mammalian brain evolution. Am. Zool. 30, 629-705.

Deaner, R. O., Isler, K., Burkart, J., and van Schaik, C. P. (2007). Overall brain size, and not encephalization quotient, best predicts cognitive ability across non-human primates. Brain Behav. Evol. 70, 115-124. doi: 10.1159/000102973

Deaner, R. O., van Schaik, C. P., and Johnson, V. (2006). Do some taxa have better domain-general cognition than others? A meta-analysis of nonhuman primate studies. Evol. Psychol. 4, 149-196.

Deary, I. J., Johnson, W., and Houlihan, L. M. (2009). Genetic foundations of human intelligence. Hum. Genet. 126, 215-232. doi: 10.1007/s00439009-0655-4
Deary, I. J., Penke, L., and Johnson, W. (2010). The neuroscience of human intelligence differences. Nat. Rev Neurosci. 11, 201-211.

Dechmann, D. K. N., and Safi, K. (2009). Comparative studies of brain evolution: a critical insight from the Chiroptera. Biol. Rev. 84, 161-172. doi 10.1111/j.1469-185X.2008.00067.x

DeFelipe, J., Alonso-Nanclares, L., and Arellano, J. I. (2002) Microstructure of the neocortex: comparative aspects. J. Neurocytol. 31, 299-316. doi: 10.1023/A:1024130211265

Delorme, A., Richard, G., and FabreThorpe, M. (2000). Ultra-rapid categorisation of natural scenes does not rely on colour cues: a study in monkeys and humans. Vision Res. 40, 2187-2200. doi: 10.1016/S00426989(00)00083-3

DeVoogd, T. J., Krebs, J. R., Healy, S. D., and Purvis, A. (1993). Relations between song repertoire size and the volume of brain nuclei related to song: comparative evolutionary analyses amongst oscine birds. Proc. Roy. Soc. B Biol. Sci. 254, 75-82.

DeYoung, C. G., Hirsh, J. B., Shane, M. S., Papademetris, X., Rajeevan, N., and Gray J. R. (2010). Testing predictions from personality neuroscience: brain structure and the Big Five. Psychol. Sci. 21, 820-828.

Dial, K. P., Greene, E., and Irschick, D. J. (2008). Allometry of behavior. Trends Ecol. Evol. 23, 394-401. doi: 10.1016/j.tree.2008.03.005

Dingemanse, N. J., Both, C., Drent, P. J., and Tinbergen, J. M. (2004). Fitness consequences of avian personalities in a fluctuating environment. Proc. Roy. Soc. B Biol. Sci. 271, 847-852. doi: 10.1098/rspb.2004.2680

Dominy, N. J., Ross, C. F., and Smith, T. D. (2004). Evolution of the special senses in primates: past, present, and future. Anat. Rec. A Discov. Mol. Cell. Evol. Biol. 281, 1078-1082.

Doran, D. M., Jungers, W. L., Sugiyama, Y., Fleagler, J. G., and Heesy, C. P (2002). "Multivariate and phylogenetic approaches to understanding chimpanzee and bonobo behavioral diversity," in Behavioural Diversity in Chimpanzees and Bonobos. eds C. Christophe Boesch, G. Hohmann, and L. F. Marchant (Cambridge: Cambridge University Press), 14-34. doi: 10.1017/СBO9780511606397.004

Dubois, E. (1897). Sur le rapport du poids de l'encéphale avec la grandeur du corps chez les mammiferres. Bull. Soc. Anthropol. Paris 8, 337-376. doi: 10.3406/bmsap.1897.5705
Dunbar, R. I. M. (1992). Neocortex size as a constraint on group size in primates. J. Hum. Evol. 22, 469-493. doi: 10.1016/0047-2484(92)90081-J

Dunbar, R. I. M. (1998). The social brain hypothesis. Evol. Anthropol. 6, 178-190.

Dunbar, R. I. M., and Shultz, S. (2007). Understanding primate brain evolution. Philos. Trans. Roy. Soc. B Biol. Sci. 362, 649-658

Ebinger, P. (1974). A cytoarchitectonic volumetric comparison of brains in wild and domestic sheep. Anat. Embryol. 144, 267-302. doi: 10.1007/BF00522811

Ebisch, S. J., Perrucci, M. G., Mercuri, P., Romanelli, R. Mantini, D., Romani, G. L., et al. (2012). Common and unique neuro-functional basis of induction, visualization, and spatial relationships as cognitive components of fluid intelligence. Neuroimage 62, 331-342. doi: $\quad 10.1016 / j . n e u r o i m a g e .2012$ 04.053

Emery, N. J. (2006). Cognitive ornithology: the evolution of avian intelligence. Philos. Trans. Roy. Soc. B Biol. Sci. 361, 23-43. doi: 10.1098/rstb.2005.1736

Emery, N. J., and Clayton, N. S. (2004). The mentality of crows: convergent evolution of intelligence in corvids and apes. Science 306, 1903-1907. doi: 10.1126/science. 1098410

Emery, N. J., Seed, A. M., von Bayern, A. M. P., and Clayton, N. S. (2007) Cognitive adaptations of social bonding in birds. Philos. Trans. Roy. Soc. B Biol. Sci. 362, 489-505. doi: 10.1098/rstb.2006.1991

Fabre-Thorpe, M., Richard, G., and Thorpe, S. J. (1998). Rapid categorization of natural images by rhesus monkeys. Neuroreport 9, 303-308. doi: 10.1097/00001756-19980126000023

Fagot, J., and Paleressompoulle, D. (2009). Automatic testing of cognitive performance in baboons maintained in social groups. Behav. Res. Methods 41, 396-404. doi 10.3758/BRM.41.2.396

Falk, D., Froese, N., Sade, D. S., and Dudek, B. C. (1999). Sex differences in brain/body relationships of Rhesus monkeys and humans. J. Hum. Evol. 36, 233-238. doi: 10.1006/jhev.1998.0273

Fears, S. C., Melega, W. P., Lee, C., Chen, K., Tu, Z., Jorgensen, M. J., et al. (2009). Identifying heritable brain phenotypes in an extended pedigree of vervet monkeys. J. Neurosci. 29, 2867-2875. doi: 10.1523/JNEUROSCI.5153-08.2009 
Felsenstein, J. (1985). Phylogenies and the comparative method. Am. Nat. 125, 1-15. doi: 10.1086/284325

Fidler, A. E., Van Oers, K., Drent, P. J., Kuhn, S., Mueller, J. C., and Kempenaers, B. (2007). Drd4 gene polymorphisms are associated with personality variation in a passerine bird. Proc. Roy. Soc. B Biol. Sci. 274, 1685-1691. doi: 10.1098/rspb.2007.0337

Finarelli, J. A. (2010). Does encephalization correlate with life history or metabolic rate in Carnivora? Biol. Lett. 6, 350-353.

Finarelli, J. A., and Flynn, J. J. (2009). Brain-size evolution and sociality in Carnivora. Proc. Natl. Acad. Sci. U.S.A. 106, 9345-9349. doi: 10.1073/pnas.0901780106

Finlay, B. L., and Darlington, R. B. (1995). Linked regularities in the development and evolution of mammalian brains. Science 268, 1578-1584. doi: 10.1126/science. 7777856

Finlay, B. L., Darlington, R. B., and Nicastro, N. (2001). Developmental structure in brain evolution. Behav. Brain Sci. 24, 263-278. doi: 10.1017/S0140525X01003958

Finlay, B. L., Hinz, F., and Darlington, R. B. (2011). Mapping behavioural evolution onto brain evolution: the strategic roles of conserved organization in individuals and species. Philos. Trans. Roy. Soc. B Biol. Sci. 366, 2111-2123.

Fischer, A., Prüfer, K., Good, J. M., Halbwax, M., Wiebe, V., André, C., et al. (2011). Bonobos fall within the genomic variation of chimpanzees. PLoS ONE 6:e21605. doi: 10.1371/journal.pone.0021605

Fitzpatrick, J. L., Almbro, M., Gonzalez-Voyer, A., Hamada, S., Pennington, C., Scanlan, J., et al. (2012). Sexual selection uncouples the evolution of brain and body size in pinnipeds. J. Evol. Biol. 25, 1321-1330. doi: 10.1111/j.1420-9101.2012.02520.x

Fize, D., Cauchoix, M., and FabreThorpe, M. (2011). Humans and monkeys share visual representations. Proc. Natl. Acad. Sci. U.S.A. 108, 7635-7640. doi: 10.1073/pnas. 1016213108

Frank, M. J., and Fossella, J. A. (2011). Neurogenetics and pharmacology of learning, motivation, and cognition. Neuropsychopharmacology 36, 133-152. doi: 10.1038/npp.2010.96

Gallup, G. G. (1970). Chimpanzees: self-recognition. Science 167, 86-87. doi: 10.1126/science.167.3914.86

Garamszegi, L. Z., Møller, A. P., and Erritzøe, J. (2002). Coevolving avian eye size and brain size in relation to prey capture and nocturnality. Proc. Roy. Soc. B Biol. Sci. 269, 961-967. doi: 10.1098/rspb.2002.1967

Gazes, R. P., Brown, E. K., Basile, B. M., and Hampton, R. R. (2013). Automated cognitive testing of monkeys in social groups yields results comparable to individual laboratory-based testing. Anim. Cogn. 16, 445-458. doi: 10.1007/ s10071-012-0585-8

Germanaud, D., Lefevre, J., Toro, R., Fischer, C., Dubois, J., HertzPannier, L., et al. (2012). Larger is twistier: Spectral Analysis of Gyrification (SPANGY) applied to adult brain size polymorphism. Neuroimage 63, 1257-1272. doi: 10.1016/j.neuroimage.2012.07.053

Gibson, K. R. (1986) "Cognition, brain size and the extraction of embedded food resources," in Primate Ontogeny, Cognition and Social Behaviour, eds J. G. Else and P. C. Lee (Cambridge: Cambridge University Press), 93-104.

Gibson, K. R. (2002). Evolution of human intelligence: the roles of brain size and mental construction. Brain Behav. Evol. 59, 10-20. doi: 10.1159/000063730

Gilbert, S. L., Dobyns, W. B., and Lahn, B. T. (2005). Genetic links between brain development and brain evolution. Nat. Rev. Genet. 6, 581-590. doi: $10.1038 / \operatorname{nrg} 1634$

Gittleman, J. L. (1986). Carnivore brain size, behavioral ecology, and phylogeny. J. Mammal. 67, 23-36. doi: $10.2307 / 1380998$

Gläscher, J., Rudrauf, D., Colom, R., Paul, L. K., Tranel, D., Damasio, H., et al. (2010). Distributed neural system for general intelligence revealed by lesion mapping. Proc. Natl. Acad. Sci. U.S.A. 107, 4705-4709. doi: 10.1073/pnas. 0910397107

Gleich, O., Schäfer, B., Kadow, C., Stuermer, I. W., and Strutz, J. (2000). Domestication differentially affects cochlear nucleus subdivisions in the gerbil. J. Comp. Neurol. $428,609-615$.

Goodson, J. L., and Kingsbury, M. A. (2011). Nonapeptides and the evolution of social group sizes in birds. Front. Neuroanat. 5:13. doi: 10.3389/fnana.2011.00013

Gosling, S. D. (2001). From mice to men: what can we learn about personality from animal research? Psychol. Bull. 127, 45-86.

Gosling, S. D. (2008). Personality in non-human animals. Soc. Pers. Psychol. Compass 2, 985-1001. doi: 10.1111/j.1751-9004.2008.00087.x

Grasso, F. W., and Basil, J. A. (2009). The evolution of flexible behavioral repertoires in cephalopod molluscs. Brain Behav. Evol. 74, 231-245. doi: 10.1159/000258669

Green, A. E., Kraemer, D. J. M., DeYoung, C. G., Fossella, J. A. and Gray, J. R. (2012). A genebrain-cognition pathway: prefrontal activity mediates the effect of COMT on cognitive control and IQ. Cereb. Cortex 23, 552-559. doi: 10.1093/cercor/bhs035

Greenberg, R. (2003). "The role of neophobia and neophilia in the development of innovative behaviour of birds," in Animal Innovation, eds S. M. Reader and K. N. Laland (Oxford: Oxford University Press), 175-196. doi: 10.1093/acprof:oso/ 9780198526223.003.0008

Greenberg, R., and Mettke-Hofmann, C. (2001). Ecological aspects of neophobia and neophilia in birds. Curr. Ornithol. 16, 119-178.

Griffin, D. R. (1976). The Question of Animal Awareness: Evolutionary Continuity of Mental Experience. New York, NY: The Rockefeller University Press.

Güntürkün, O. (2005). The avian "prefrontal cortex" and cognition. Curr. Opin. Neurobiol. 15, 686-693. doi: 10.1016/j.conb.2005.10.003

Güntürkün, O. (2012). The convergent evolution of neural substrates for cognition. Psychol. Res. 76, 212-219. doi: 10.1007/s00426-011-0377-9

Hager, R., Lu, L., Rosen, G. D. and Williams, R. W. (2012). Genetic architecture supports mosaic brain evolution and independent brain-body size regulation. Nat. Commun. 3:1079. doi $10.1038 /$ ncomms 2086

Hare, B. (2009). "What is the effect of affect on Bonobo and Chimpanzee Problem Solving?" in The Neurobiology of "Umwelt": How Living Beings Perceive the world, eds A. Berthoz and Y. Christen (Berlin Springer Press), 89-102.

Hartwig, W., Rosenberger, A. L., Norconk, M. A., and Owl, M. Y. (2011). Relative brain size, gut size, and evolution in New World monkeys. Anat. Rec. Adv. Integr. Anat. Evol. Biol. 294, 2207-2221. doi: 10.1002/ar.21515

Harvey, P. H., and Krebs, J. R. (1990). Comparing brains. Science 249, 140-146. doi: 10.1126/science. 2196673

Harvey, P. H., and Pagel, M. D. (1991). The Comparative Method in Evolutionary Biology. Oxford: Oxford University Press.

Healy, S. D., and Hurly, T. A. (2013) What hummingbirds can tell us about cognition in the wild. Comp Cogn. Behav. Rev. 8, 13-28.
Healy, S. D., and Rowe, C. (2007) A critique of comparative studies on brain size. Proc. Roy. Soc. B Biol. Sci. 274, 453-464. doi: 10.1098/rspb.2006.3748

Heilbronner, S. R., Rosati, A. G., Stevens, J. R., Hare, B., and Hauser, M. D. (2008). A fruit in the hand or two in the bush? Divergent risk preferences in chimpanzees and bonobos. Biol. Lett. 4, 246-249. doi: 10.1098/rsbl.2008.0081

Herculano-Houzel, S. (2007). Encephalization, neuronal excess, and neuronal index in rodents. Anat. Rec. Adv. Integr. Anat. Evol. Biol. 290, 1280-1287. doi: 10.1002/ar.20598

Herculano-Houzel, S. (2010). Coordinated scaling of cortical and cerebellar numbers of neurons. Front. Neuroanat. 4:12. doi: 10.3389/fnana.2010.00012

Herculano-Houzel, S. (2011a). Brains matter, bodies maybe not: the case for examining neuron numbers irrespective of body size. Ann. N. Y. Acad. Sci. 1225, 191-199.

Herculano-Houzel, S. (2011b). Not all brains are made the same: new views on brain scaling in evolution. Brain Behav. Evol. 78, 22-36.

Herculano-Houzel, S., and Kaas, J. H. (2011). Gorilla and orangutan brains conform to the primate cellular scaling rules: implications for human evolution. Brain Behav. Evol. 77, 33-44. doi: 10.1159/000322729

Herrmann, E., and Call, J. (2012). Are there geniuses among the apes? Philos. Trans. Roy. Soc. B Biol. Sci. 367, 2753-2761.

Herrmann, E., Hare, B., Call, J., and Tomasello, M. (2010). Differences in the cognitive skills of bonobos and chimpanzees. PLoS ONE 5:e12438. doi: 10.1371/journal.pone.0012438

Heymann, E. W. (2006). The neglected sense-olfaction in primate behavior, ecology, and evolution. Am. J. Primatol. 68, 519-524. doi: 10.1002/ajp.20249

Heymsfield, S. B., Müller, M. J., BosyWestphal, A., Thomas, D., and Shen, W. (2012). Human brain mass: similar body composition associations as observed across mammals. Am. J. Hum. Biol. 24, 479-485. doi: 10.1002/ajhb.22249

Hladik, C. M., Chivers, D. J., and Pasquet, P. (1999). On diet and gut size in non-human primates and humans: is there a relationship to brain size? Curr. Anthropol. 40, 695-697.

Hochner, B., Shomrat, T., and Fiorito, G. (2006). The octopus: a model for a comparative analysis of the evolution of learning and memory 
mechanisms. Biol. Bull. 210, 308-317. doi: 10.2307/4134567

Hofman, M. A. (1989). On the evolution and geometry of the brain in mammals. Prog. Neurobiol. 32, 137-158. doi: 10.1016/0301-0082(89)90013-0

Holloway, R. L. (1980). Within-species brain-body weight variability: a reexamination of the Danish data and other primate species. Am. J. Phys. Anthropol. 53, 109-121. doi: 10.1002/ajpa.1330530115

Hopkins, W. D., Lyn, H., and Cantalupo, C. (2009). Volumetric and lateralized differences in selected brain regions of chimpanzees (Pan troglodytes) and bonobos (Pan paniscus). Am. J. Primatol. 71, 988-997. doi: 10.1002/ajp.20741

Humphrey, N. K. (1976). "The social function of intellect," in Growing Points in Ethology, eds P. P. G. Bateson and R. A. Hinde (New York, NY: Cambridge University Press), 303-317.

Hutsler, J. J., Lee, D. G., and Porter, K. K. (2005). Comparative analysis of cortical layering and supragranular layer enlargement in rodent carnivore and primate species. Brain Res. 1052, 71-81. doi: 10.1016/j.brainres.2005.06.015

Ikeda, Y. (2009). A perspective on the study of cognition and sociality of cephalopod mollusks, a group of intelligent marine invertebrates1. Jpn. Psychol. Res. 51, 146-153. doi: 10.1111/j.1468-5884.2009.00401.x

Imamizu, H., Miyauchi, S., Tamada, T., Sasaki, Y., Takino, R., Pütz, B., et al. (2000). Human cerebellar activity reflecting an acquired internal model of a new tool. Nature 403 , 192-195. doi: 10.1038/35003194

Isler, K., Kirk, E. C., Miller, J., Albrecht, G. A., Gelvin, B. R., and Martin, R. D. (2008). Endocranial volumes of primate species: scaling analyses using a comprehensive and reliable data set. J. Hum. Evol. 55, 967-978. doi: 10.1016/j.jhevol.2008. 08.004

Isler, K., and van Schaik, C. P. (2006). Metabolic costs of brain size evolution. Biol. Lett. 2, 557-560. doi: 10.1098/rsbl.2006.0538

Iwaniuk, A. N., Dean, K. M., and Nelson, J. E. (2004). A mosaic pattern characterizes the evolution of the avian brain. Proc. Roy. Soc. B Biol. Sci. 271, S148-S151.

Iwaniuk, A. N., and Hurd, P. L. (2005). The evolution of cerebrotypes in birds. Brain Behav. Evol. 65, 215-230. doi: 10.1159/000084313

Jacobs, L. F. (1996). The economy of winter: phenotypic plasticity in behavior and brain structure. Biol. Bull. 191, 92-100. doi: 10.2307/1543068

Jacobs, L. F. (2012). From chemotaxis to the cognitive map: the function of olfaction. Proc. Natl. Acad. Sci. U.S.A. 109, 10693-10700. doi: 10.1073/pnas.1201880109

Jerison, H. J. (1973). Evolution of the Brain and Intelligence. New York, NY: Academic Press.

Jerison, H. J. (1985). Animal intelligence as encephalization [and Discussion]. Philos. Trans. Roy. Soc. B Biol. Sci. 308, 21-35. doi: 10.1098/rstb.1985.0007

Jerison, H. J. (1993). Number of our days: quantifying social evolution. Behav. Brain Sci. 16, 712-713. doi: 10.1017/S0140525X00032556

Johnson, V. E., Deaner, R. O., and van Schaik, C. P. (2002). Bayesian analysis of rank data with application to primate intelligence experiments. J. Am. Stat. Assoc. 97, 8-17. doi: 10.1198/016214502753479185

Johnson, W., Jung, R. E., Colom, R., and Haier, R. J. (2008). Cognitive abilities independent of IQ correlate with regional brain structure. Intelligence 36, 18-28. doi: 10.1016/j.intell.2007.01.005

Jones, K. E., and MacLarnon, A. M. (2004). Affording larger brains: testing hypotheses of mammalian brain evolution on bats. Am. Nat. 164, 20-31. doi: $10.1086 / 421334$

Kaas, J. H. (2000). Why is brain size so important: design problems and solutions as neocortex gets bigger or smaller. Brain Mind 1, 7-23. doi: 10.1023/A:1010028405318

Kamil, A. (1987). A synthetic approach to the study of animal intelligence. Nebr. Symp. Motiv. 7, 257-308.

Kanai, R., and Rees, G. (2011). The structural basis of inter-individual differences in human behaviour and cognition. Nat. Rev. Neurosci. 12, 231-242. doi: 10.1038/nrn3000

Kaskan, P. M., Franco, E. C. S., Yamada, E. S., de Lima Silveira, L. C., Darlington, R. B., and Finlay, B. L. (2005). Peripheral variability and central constancy in mammalian visual system evolution. Proc. Roy. Soc. B Biol. Sci. 272, 91-100. doi: 10.1098/rspb.2004.2925

Katz, P. S. (2011). Neural mechanisms underlying the evolvability of behaviour. Philos. Trans. Roy. Soc. B Biol. Sci. 366, 2086-2099. doi: 10.1098/rstb.2010.0336

Kirk, E. C. (2006). Visual influences on primate encephalization. J. Hum. Evol. 51, 76-90. doi: 10.1016/j.jhevol.2006.01.005

Kirkcaldie, M. T. K., and Kitchener, P. D. (2007). When brains expand: mind and the evolution of cortex. Acta Neuropsychiatr. 19, 139-148. doi 10.1111/j.1601-5215.2007.00204.x

Kirsch, J. A., Güntürkün, O., and Rose, J. (2008). Insight without cortex: lessons from the avian brain. Conscious. Cogn. 17, 475-483. doi: 10.1016/j.concog.2008.03.018

Kolb, E. M., Rezende, E. L., Holness, L. Radtke, A., Lee, S. K., Obenaus, A., et al. (2013). Mice selectively bred for high voluntary wheel running have larger midbrains: support for the mosaic model of brain evolution. J. Exp. Biol. 216, 515-523. doi: 10.1242/jeb.076000

Kotrschal, A., Rogell, B., Bundsen, A., Svensson, B., Zajitschek, S., Brännström, I., et al. (2013). Artificial selection on relative brain size in the guppy reveals costs and benefits of evolving a larger brain. Curr. Biol. 23, 1-4. doi: 10.1016/j.cub.2012.11.058

Krebs, J. R., Sherry, D. F., Healy, S. D., Perry, V. H., and Vaccarino, A. L. (1989). Hippocampal specialization of food-storing birds. Proc. Natl. Acad. Sci. U.S.A. 86, 1388-1392. doi: 10.1073/pnas.86.4.1388

Krubitzer, L. A., and Seelke, A. M. H. (2012). Cortical evolution in mammals: the bane and beauty of phenotypic variability. Proc. Natl. Acad Sci. U.S.A. 109, 10647-10654. doi: 10.1073/pnas.1201891109

Kruska, D. C. T. (1988). Effects of domestication on brain structure and behavior in mammals. Hum. Evol. 3, 473-485. doi: 10.1007/BF02436333

Kruska, D. C. T. (2005). On the evolutionary significance of encephalization in some eutherian mammals: effects of adaptive radiation, domestication, and feralization. Brain Behav. Evol. 65, 73-108. doi: 10.1159/000082979

Kruska, D. C. T. (1996). The effect of domestication on brain size and composition in the mink (Mustela vison). J. Zool. 239, 645-661. doi: 10.1111/j.14697998.1996.tb05468.x

Kruska, D. C. T. (2007). The effects of domestication on brain size. Evol. Nerv. Syst. 3, 143-153. doi: 10.1016/B0-12-370878-8/00054-9

Kukekova, A. V., Temnykh, S. V., Johnson, J. L., Trut, L. N., and Acland, G. M. (2012). Genetics of behavior in the silver fox Mamm. Genome 23, 164-177. doi 10.1007/s00335-011-9373-z

Lee, J. J. (2007). A "g" beyond Homo sapiens? Some hints and suggestions. Intelligence 35, 253-265. doi: 10.1016/j.intell.2006.08.003
Lefebvre, L. (2012). Primate encephalization. Prog. Brain Res. 195, 393-412. doi: 10.1016/B978-0-44453860-4.00019-2

Lefebvre, L., and Bolhuis, J. J. (2003). "Positive and negative correlates of feeding innovations in birds: evidence for limited modularity," in Animal Innovation, eds S. M. Reader and K. N. Laland (Oxford: Oxford University Press), 39-61.

Lefebvre, L., Reader, S. M., and Boire, D. (2006). "The evolution of encephalization," in Evolution of Nervous Systems Volume 1: History of Ideas, Basic Concepts and Developmental Mechanisms, eds G. F. Striedter and J. L. R. Rubenstein (Oxford: Academic Press), 121-141.

Leiner, H. C., Leiner, A. L., and Dow, R. S. (1991). The human cerebrocerebellar system: its computing, cognitive and language skills. Behav. Brain Res. 44, 113-128. doi 10.1016/S0166-4328(05)80016-6

Lemaittre, J. F., Ramm, S. A., Barton, R. A., and Stockley, P. (2009). Sperm competition and brain size evolution in mammals. J. Evol. Biol. 22, 2215-2221. doi: 10.1111/j.14209101.2009.01837.x

Lim, M. M., Wang, Z., Olazábal, D. E., Ren, X., Terwilliger, E. F., and Young, L. J. (2004). Enhanced partner preference in a promiscuous species by manipulating the expression of a single gene. Nature 429, 754-757. doi: 10.1038/nature02539

Lindenfors, P., Nunn, C. L., and Barton, R. A. (2007). Primate brain architecture and selection in relation to sex. BMC Biol. 5:20. doi: 10.1186/1741-7007-5-20

Lipp, H. P., and Wolfer, D. P. (2002) Big brains for bad genes: nonmental correlates of encephalization. Evol. Anthropol. 11, 126-131. doi: 10.1002/evan.10074

Locurto, C. (2007). Individual differences and animal personality. Comp. Cogn. Behav. Rev. 2, 67-78.

Lotem, A., and Halpern, J. Y. (2012). Coevolution of learning and dataacquisition mechanisms: a model for cognitive evolution. Philos. Trans. Roy. Soc. B Biol. Sci. 367, 2686-2694

MacLarnon, A. (1996). The scaling of gross dimensions of the spinal cord in primates and other species. J. Hum. Evol. 30, 71-87. doi: 10.1006/jhev.1996.0005

MacLean, E. L., Matthews, L. J., Hare, B. A., Nunn, C. L., Anderson, R. C., Aureli, F., et al. (2012). How does cgnition evolve? Phylogenetic comparative psychology. Anim. Cogn. 15, 223-238. doi: 10.1007/s10071011-0448-8 
Mahmood, S., Ahmad, W., and Hassan, M. J. (2011). Autosomal recessive primary microcephaly (MCPH): clinical manifestations, genetic heterogeneity and mutation continuum. Orphanet J. Rare Dis. 6:39. doi: 10.1186/17501172-6-39

Manzini, M. C., and Walsh, C. A. (2011). What disorders of cortical development tell us about the cortex: one plus one does not always make two. Curr. Opin. Genet. Dev. 21, 333-339. doi: 10.1016/j.gde.2011.01.006

Marino, L. (2006). Absolute brain size: did we throw the baby out with the bathwater? Proc. Natl. Acad. Sci. U.S.A. 103, 13563-13564.

Marino, L., and Frohoff, T. (2011). Towards a new paradigm of noncaptive research on Cetacean cognition. PLOS ONE 6:e24121. doi: 10.1371/journal.pone.0024121

Martin, R. D. (1981). Relative brain size and basal metabolic rate in terrestrial vertebrates. Nature 293, 57-60. doi: 10.1038/293057a0

Martin, R. D. (1996). Scaling of the mammalian brain: the maternal energy hypothesis. Physiology 11, 149-156.

Martin, R. D., Genoud, M., and Hemelrijk, C. K. (2005). Problems of allometric scaling analysis: examples from mammalian reproductive biology. J. Exp. Biol. 208, 1731-1747. doi: 10.1242/jeb.01566

Matzel, L. D., Wass, C., and Kolata, S. (2011). Individual differences in animal intelligence: learning, reasoning, selective attention and interspecies conservation of a cognitive trait. Int. J. Comp. Psychol. 24, 36-59.

McDaniel, M. A. (2005). Big-brained people are smarter: a meta-analysis of the relationship between in vivo brain volume and intelligence. Intelligence 33, 337-346. doi: 10.1016/j.intell.2004.11.005

Menzel, R., and Giurfa, M. (2001). Cognitive architecture of a minibrain: the honeybee. Trends Cogn. Sci. 5, 62-71. doi: 10.1016/S13646613(00)01601-6

Merker, B. (2004). Cortex, countercurrent context, and dimensional integration of lifetime memory. Cortex 40, 559-576. doi: 10.1016/S00109452(08)70148-5

Mettke-Hofmann, C., Wink, M., Winkler, H., and Leisler, B. (2005). Exploration of environmental changes relates to lifestyle. Behav. Ecol. 16, 247-254. doi: 10.1093/beheco/arh159

Mettke-Hofmann, C., Winkler, H., and Leisler, B. (2002). The significance of ecological factors for exploration and neophobia in parrots. Ethology 108, 249-272. doi: 10.1046/j.14390310.2002.00773.x

Milton, K. (1981). Distribution patterns of tropical plant foods as an evolutionary stimulus to primate mental development. Am. Anthropol. 83, 534-548. doi: 10.1525/aa.1981.83.3.02a00020

Mlikovsky, J. (1989). Brain size in birds. 2. Falconiformes through Gaviiformes. Vést. Čs. Společ. Zool. 53, 200-213.

Mohammed, A. H., Zhu, S. W., Darmopil, S., Hjerling-Leffler, J., Ernfors, P., Winblad, B., et al. (2002). Environmental enrichment and the brain. Prog. Brain Res. 138, 109-133. doi: 10.1016/S0079-6123(02)38074-9

Møller, A. (2010). Brain size, head size and behaviour of a passerine bird. J. Evol. Biol. 23, 625-635. doi: 10.1111/j.1420-9101.2009.01928.x

Molnár, Z., Métin, C., Stoykova, A., Tarabykin, V., Price, D. J., Francis, F., et al. (2006). Comparative aspects of cerebral cortical development. Eur. J. Neurosci. 23, 921-934. doi: 10.1111/j.1460-9568.2006.04611.x

Montgomery, S. H., Capellini, I., Barton, R. A., and Mundy, N. I. (2010). Reconstructing the ups and downs of primate brain evolution: implications for adaptive hypotheses and Homo floresiensis. BMC Biol. 8:9. doi: 10.1186/1741-7007-8-9

Morriss-Kay, G. M., and Wilkie, A. O. M. (2005). Growth of the normal skull vault and its alteration in craniosynostosis: insights from human genetics and experimental studies. J. Anat. 207, 637-653. doi: 10.1111/j.1469-7580.2005.00475.x

Morwood, M., Brown, P., Sutikna, T., Saptomo, E., Westaway, K., Due, R., et al. (2005). Further evidence for small-bodied hominins from the Late Pleistocene of Flores, Indonesia. Nature 437, 1012-1017. doi: 10.1038/nature04022

Navarrete, A., van Schaik, C. P., and Isler, K. (2011). Energetics and the evolution of human brain size. Nature 480, 91-93. doi: 10.1038/nature 10629

Nealen, P. M., and Ricklefs, R. E. (2001). Early diversification of the avian brain: body relationship. J. Zool. 253, 391-404. doi: 10.1017/S095283690100036X

Netchine, I., Azzi, S., Le Bouc, Y., and Savage, M. O. (2011). IGF1 molecular anomalies demonstrate its critical role in fetal, postnatal growth and brain development. Best Pract. Res. Clin.
Endocrinol. Metab. 25, 181-190. doi: 10.1016/j.beem.2010.08.005

Nimchinsky, E. A., Gilissen, E., Allman, J. M., Perl, D. P., Erwin, J. M. and Hof, P. R. (1999). A neuronal morphologic type unique to humans and great apes. Proc. Natl. Acad. Sci. U.S.A. 96, 5268-5273. doi: 10.1073/pnas.96.9.5268

Niven, J. E. (2005). Brain evolution: getting better all the time? Curr. Biol. 15, 624-626.

O'Connor, M. P., Agosta, S. J., Hansen, F., Kemp, S. J., Sieg, A. E., McNair J. N., et al. (2007). Phylogeny, regression, and the allometry of physiological traits. Am. Nat. 170, 431-442. doi: 10.1086/519459

Pakkenberg, B., and Gundersen, H. J. G. (1997). Neocortical neuron number in humans: effect of sex and age J. Comp. Neurol. 384, 312-320.

Parker, C. E. (1974). Behavioral diversity in ten species of nonhuman primates. J. Comp. Physiol. Psychol. 87, 930-937. doi: 10.1037/h0037228

Parker, S. T., and Gibson, K. R. (1977). Object manipulation, tool use and sensorimotor intelligence as feeding adaptations in Cebus monkeys and great apes. J. Hum. Evol. 6 , 623-641. doi: 10.1016/S0047-2484 (77) $80135-8$

Paulin, M. G. (1993). The role of the cerebellum in motor control and perception. Brain Behav. Evol. 41, 39-50. doi: 10.1159/000113822

Pelé, M., Micheletta, J., Uhlrich, P., Thierry, B., and Dufour, V. (2011). Delay maintenance in Tonkean macaques (Macaca tonkeana) and brown capuchin monkeys (Cebus apella). Int. J. Primatol. 32, 149-166 doi: 10.1007/s10764-010-9446-y

Peters, M., Jäncke, L., Staiger, J., Schlaug, G., Huang, Y., and Steinmetz, H. (1998). Unsolved problems in comparing brain sizes in Homo sapiens. Brain Cogn. 37 254-285. doi: 10.1006/brcg.1998 0983

Pilbeam, D., and Gould, S. J. (1974). Size and scaling in human evolution. Science 186, 892-901. doi 10.1126/science.186.4167.892

Pillay, P., and Manger, P. R. (2007). Order-specific quantitative patterns of cortical gyrification. Eur J. Neurosci. 25, 2705-2712. doi 10.1111/j.1460-9568.2007.05524.x

Pitnick, S., Jones, K. E., and Wilkinson, G. S. (2006). Mating system and brain size in bats. Proc. Roy. Soc. B Biol. Sci. 273, 719-724. doi 10.1098/rspb.2005.3367

Plomin, R. (1990). The role of inheritance in behavior. Science 248 183-188. doi: 10.1126/science.218 3351
Plotnik, J. M., de Waal, F. B. M., and Reiss, D. (2006). Self-recognition in an Asian elephant. Proc. Natl. Acad. Sci. U.S.A. 103, 17053-17057. doi: 10.1073/pnas.0608062103

Pollen, A. A., and Hofmann, H. A. (2008). Beyond neuroanatomy: novel approaches to studying brain evolution. Brain Behav. Evol. 72, 145-158. doi: 10.1159/000151474

Preuss, T. M. (2007). "Primate brain evolution in phylogenetic context," in Evolution of Nervous Systems, Volum 4: The Evolution of Primate Nervous Systems, eds J. H. Kaas and T. M. Preuss (Oxford: Elsevier), 3-34.

Price, E. O. (1999). Behavioral development in animals undergoing domestication. Appl. Anim. Behav. Sci. 65, 245-271. doi: 10.1016/S01681591(99)00087-8

Prior, H., Schwarz, A., and Güntürkün, O. (2008). Mirrorinduced behavior in the magpie (Pica pica): evidence of selfrecognition. PLoS Biol. 6:e202. doi: 10.1371/journal.pbio.0060202

Purvis, A. (1995). A composite estimate of primate phylogeny. Philos. Trans. Roy. Soc. B Biol. Sci. 348, 405-421. doi: 10.1098/rstb.1995.0078

R Development Core Team. (2011). R: A Language and Environment for Statistical Computing. R Foundation for Statistical Computing, Vienna. Available online at: http://www.Rproject.org/. ISBN 3-900051-07-0.

Rabaglia, C. D., Marcus, G. F., and Lane, S. P. (2011). What can individual differences tell us about the specialization of function? $\operatorname{Cog} n$. Neuropsychol. 28, 288-303.

Ramnani, N. (2006). The primate cortico-cerebellar system: anatomy and function. Nat. Rev. Neurosci. 7 , 511-522. doi: 10.1038/nrn1953

Reader, S. M., Hager, Y., and Laland, K. N. (2011). The evolution of primate general and cultural intelligence. Philos. Trans. Roy. Soc. B Biol. Sci. 366, 1017-1027. doi: 10.1098/rstb.2010.0342

Réale, D., Dingemanse, N. J., Kazem, A. J. N., and Wright, J. (2010). Evolutionary and ecological approaches to the study of personality. Philos. Trans. Roy. Soc. B Biol. Sci. 365, 3937-3946. doi: 10.1098/rstb.2010.0222

Réale, D., Reader, S. M., Sol, D., McDougall, P. T., and Dingemanse, N. J. (2007). Integrating animal temperament within ecology and evolution. Biol. Rev. 82, 291-318. doi: 10.1111/j.1469-185X.2007.00010.x

Reep, R. L., Finlay, B. L., and Darlington, R. B. (2007). The 
limbic system in mammalian brain evolution. Brain Behav. Evol. 70, 57-70. doi: 10.1159/000101491

Rehkämper, G., Frahm, H. D., and Cnotka, J. (2008). Mosaic evolution and adaptive brain component alteration under domestication seen on the background of evolutionary theory. Brain Behav. Evol. 71, 115-126. doi: 10.1159/ 000111458

Rehkämper, G., Kart, E., Frahm, H. D., and Werner, C. W. (2003). Discontinuous variability of brain composition among domestic chicken breeds. Brain Behav. Evol. 61, 59-69. doi: 10.1159/000069352

Reiss, D., and Marino, L. (2001). Mirror self-recognition in the bottlenose dolphin: a case of cognitive convergence. Proc. Natl. Acad. Sci. U.S.A. 98, 5937-5942. doi: 10.1073/pnas. 101086398

Rilling, J. K. (2006). Human and nonhuman primate brains: are they allometrically scaled versions of the same design? Evol. Anthropol. 15, 65-77.

Rilling, J. K., and Insel, T. R. (1998). Evolution of the cerebellum in primates: differences in relative volume among monkeys, apes and humans. Brain Behav. Evol. 52, 308-314. doi: 10.1159/000006575

Rilling, J. K., and Insel, T. R. (1999). The primate neocortex in comparative perspective using magnetic resonance imaging. J. Hum. Evol. 37, 191-223. doi: 10.1006/jhev.1999.0313

Rilling, J. K., Scholz, J., Preuss, T. M., Glasser, M. F., Errangi, B. K., and Behrens, T. E. (2012). Differences between chimpanzees and bonobos in neural systems supporting social cognition. Soc. Cogn. Affect. Neurosci. 7, 369-379. doi: $10.1093 /$ scan/nsr017

Ringo, J. L. (1991). Neuronal interconnection as a function of brain size. Brain Behav. Evol. 38, 1-6. doi: 10.1159/000114375

Robinson, D. L. (2001). How brain arousal systems determine different temperament types and the major dimensions of personality. Pers. Individ. Diff. 31, 1233-1259. doi: 10.1016/S01918869(00)00211-7

Rosa, M. G. P., and Tweedale, R. (2005). Brain maps, great and small: lessons from comparative studies of primate visual cortical organization. Philos. Trans. Roy. Soc. B Biol. Sci. 360, 665-691. doi: 10.1098/rstb.2005.1626

Rosati, A. G., Stevens, J. R., Hare, B., and Hauser, M. D. (2007). The evolutionary origins of human patience: temporal preferences in chimpanzees, bonobos, and human adults. Curr. Biol. 17, 1663-1668. doi: 10.1016/j.cub.2007.08.033

Roth, T. C., Brodin, A., Smulders, T. V., LaDage, L. D., and Pravosudov, V. V. (2010). Is bigger always better? A critical appraisal of the use of volumetric analysis in the study of the hippocampus. Philos. Trans. Roy. Soc. B Biol. Sci. 365, 915-931. doi: 10.1098/rstb.2009.0208

Sacher, G. A. (1959). "The lifespan of animals," in C.I.B.A. Foundation Symposium on Ageing, eds G. E. W. Wolstenholme and M. O'Connor (Boston, MA: Little Brown), 115-133.

Saetre, P., Lindberg, J., Leonard, J. A., Olsson, K., Pettersson, U., Ellegren, H., et al. (2004). From wild wolf to domestic dog: gene expression changes in the brain. Mol. Brain Res. 126, 198-206. doi: 10.1016/j.molbrainres.2004.05.003

Safi, K., Seid, M. A., and Dechmann, D. K. N. (2005). Bigger is not always better: when brains get smaller. Biol. Lett. 1, 283-286. doi: 10.1098/rsbl.2005.0333

Scheiber, I. B. R., Weiß, B. M., Hirschenhauser, K., Wascher, C. A. F., Nedelcu, I. T., and Kotrschal, K. (2008). Does "Relationship Intelligence" make big brains in birds? Open Biol. J. 1, 6-8.

Schmitt, V., Pankau, B., and Fischer, J. (2012). Old world monkeys compare to apes in the primate cognition test battery. PLOS ONE 7:e32024. doi: 10.1371/journal. pone. 0032024

Schoenemann, P. T. (2004). Brain size scaling and body composition in mammals. Brain Behav. Evol. 63, 47-60. doi: 10.1159/000073759

Schoenemann, P. T., Budinger, T. F., Sarich, V. M., and Wang, W. S. Y. (2000). Brain size does not predict general cognitive ability within families. Proc. Natl. Acad. Sci. U.S.A. 97, 4932-4937. doi: 10.1073/pnas.97.9.4932

Schuett, W., Tregenza, T., and Dall, S. R. X. (2010). Sexual selection and animal personality. Biol. Rev. 85, 217-246. doi: 10.1111/j.1469185X.2009.00101.X

Semendeferi, K., and Damasio, H. (2000). The brain and its main anatomical subdivisions in living hominoids using magnetic resonance imaging. J. Hum. Evol. 38, 317-332. doi: 10.1006/jhev.1999.0381

Sherry, D. F., and Hoshooley, J. S. (2010). Seasonal hippocampal plasticity in food-storing birds. Philos. Trans. Roy. Soc.
B Biol. Sci. 365, 933-943. doi 10.1098/rstb.2009.0220

Sherwood, C. C., Cranfield, M. R., Mehlman, P. T., Lilly, A. A., Garbe, J. A. L., Whittier, C. A., et al. (2004). Brain structure variation in great apes, with attention to the mountain gorilla (Gorilla beringe beringei). Am. J. Primatol. 63, 149-164. doi: 10.1002/ajp.20048

Shettleworth, S. J. (2001). Animal cognition and animal behaviour Anim. Behav. 61, 277-286. doi: 10.1006/anbe.2000.1606

Shiner, R. L., and DeYoung, C. G. (2013). "The structure of temperament and personality traits: a developmental perspective," in The Oxford Handbook of Developmental Psychology, Vol. 2: Self and Other ed P. D. Zelazo (New York, NY: Oxford University Press), 113-141.

Shoshani, J., Kupsky, W. J., and Marchant, G. H. (2006). Elephant brain: Part I: gross morphology, functions, comparative anatomy, and evolution. Brain Res. Bull. 70, 124-157. doi 10.1016/j.brainresbull.2006.03.016

Sih, A., Bell, A., and Johnson, J. C. (2004). Behavioral syndromes: an ecological and evolutionary overview. Trends Ecol. Evol. 19, 372-378. doi: 10.1016/j.tree.2004.04.009

Sih, A., and Del Giudice, M. (2012). Linking behavioural syndromes and cognition: a behavioural ecology perspective. Philos. Trans. Roy. Soc. B Biol. Sci. 367, 2762-2772.

Simpson, J., and Kelly, J. P. (2011) The impact of environmental enrichment in laboratory rats-Behavioural and neurochemical aspects. Behav Brain Res. 222, 246-264. doi 10.1016/j.bbr.2011.04.002

Smaers, J. B., Dechmann, D. K. N. Goswami, A., Soligo, C., and Safi, K. (2012a). Comparative analyses of evolutionary rates reveal different pathways to encephalization in bats, carnivorans, and primates. Proc. Natl. Acad. Sci. U.S.A. 109, 18006-18011. doi: 10.1073/pnas.1212181109

Smaers, J. B., Mulvaney, P., Soligo, C. Zilles, K., and Amunts, K. (2012b). Sexual dimorphism and laterality in the evolution of the primate prefrontal cortex. Brain Behav. Evol. 79, 3; 205-212.

Smaers, J. B., and Soligo, C. (2013) Brain reorganization, not relative brain size, primarily characterizes anthropoid brain evolution. Proc. Roy. Soc. B. Biol. Sci. 280:1759.

Smaers, J. B., Steele, J., Case, C. R., Cowper, A., Amunts, K., and Zilles,
K. (2011a). Primate prefrontal cortex evolution: human brains are the extreme of a lateralized ape trend. Brain Behav. Evol. 77, 67-78.

Smaers, J. B., Steele, J., and Zilles, K. (2011b). Modeling the evolution of cortico-cerebellar systems in primates. Ann. N.Y. Acad. Sci. 1225, 176-190.

Smith, B. R., and Blumstein, D. T. (2008). Fitness consequences of personality: a meta-analysis. Behav. Ecol. 19, 448-455. doi: 10.1093/beheco/arm144

Smith, T. D., and Bhatnagar, K. P. (2004). Microsmatic primates: reconsidering how and when size matters. Anat. Rec. B New Anat. 279, 24-31.

Smulders, T. V., Gould, K. L., and Leaver, L. A. (2010). Using ecology to guide the study of cognitive and neural mechanisms of different aspects of spatial memory in foodhoarding animals. Philos. Trans. Roy. Soc. B Biol. Sci. 365, 883-900. doi: 10.1098/rstb.2009.0211

Sol, D. (2009). Revisiting the cognitive buffer hypothesis for the evolution of large brains. Biol. Lett. 5, 130-133. doi: 10.1098/rsbl.2008.0621

Speakman, J. R. (2005). Body size, energy metabolism and lifespan. J. Exp. Biol. 208, 1717-1730. doi: 10.1242/jeb.01556

Stamps, J., and Groothuis, G. G. (2010). The development of animal personality: relevance, concepts and perspectives. Biol. Rev. 85, 301-325. doi: $\quad 10.1111 / j .1469-185 X .2009$. 00103.x

Stephan, H., Frahm, H., and Baron, G. (1981). New and revised data on volumes of brain structures in insectivores and primates. Folia Primatol. 35, 1-29. doi: 10.1159/000155963

Stevens, C. F. (2001). An evolutionary scaling law for the primate visual system and its basis in cortical function. Nature 411, 193-195. doi: $10.1038 / 35075572$

Stevens, J. R., Hallinan, E. V., and Hauser, M. D. (2005). The ecology and evolution of patience in two New World monkeys. Biol. Lett. 1, 223-226. doi: 10.1098/rsbl.2004.0285

Strasser, A., and Burkart, J. M. (2012). Can we measure brain efficiency? An empirical test with Common Marmosets (Callithrix jacchus). Brain Behav. Evol. 80, 26-40. doi: 10.1159/000338014

Striedter, G. F. (2002). Brain homology and function: an uneasy alliance. Brain Res. Bull. 57, 239-242. doi: 10.1016/S0361-9230(01)00692-X 
Striedter, G. F. (2005). Principles of Brain Evolution. Sunderland, MA: Sinauer Associates.

Striedter, G. F. (2006). Précis of principles of brain evolution. Behav. Brain Sci. 29, 1-11. doi: 10.1017/S0140525X06009010

Sultan, F. (2002). Analysis of mammalian brain architecture. Nature 415, 133-134. doi: 10.1038/415133b

Sultan, F., and Glickstein, M. (2007). The cerebellum: comparative and animal studies. Cerebellum 6, 168-176. doi: 10.1080/14734220701332486

Thompson, P., Cannon, T. D., and Toga, A. W. (2002). Mapping genetic influences on human brain structure. Ann. Med. 34, 523-536. doi: $10.1080 / 078538902321117733$

Thornton, A., and Lukas, D. (2012). Individual variation in cognitive performance: developmental and evolutionary perspectives. Philos. Trans. Roy. Soc. B Biol. Sci. 367, 2773-2783.

Tomasello, M., and Call, J. (2011). Methodological challenges in the study of primate cognition. Science 334, 1227-1228. doi: 10.1126/science. 1213443

Tramontin, A. D., and Brenowitz, E. A. (2000). Seasonal plasticity in the adult brain. Trends Neurosci. 23, 251-258. doi: 10.1016/S01662236(00)01558-7

Trut, L. (1999). Early Canid domestication: The Farm-Fox experiment. Am. Scientist 87, 160-169.

Trut, L., Oskina, I., and Kharlamova, A. (2009). Animal evolution during domestication: the domesticated fox as a model. Bioessays 31, 349-360. doi: 10.1002/bies.200800070

Uher, J. (2011). Individual behavioral phenotypes: an integrative meta-theoretical framework. Why "behavioral syndromes" are not analogs of "personality." Dev Psychobiol. 53, 521-548. doi: $10.1002 / \mathrm{dev} .20544$

Uher, J., and Asendorpf, J. B. (2008). Personality assessment in the Great Apes: comparing ecologically valid behavior measures, behavior ratings, and adjective ratings. J. Res. Pers. 42, 821-838 doi: 10.1016/j.jrp.2007.10.004

van Schaik, C. P., Isler, K., and Burkart, J. M. (2012). Explaining brain size variation: from social to cultural brain. Trends Cogn. Sci. 16, 277-284. doi: 10.1016/j.tics.2012.04.004

Vauclair, J., Fagot, J., and Hopkins, W. D. (1993). Rotation of mental images in baboons when the visual input is directed to the left cerebral hemisphere. Psychol. Sci. 4, 99-103. doi: 10.1111/j.14679280.1993.tb00468.x

Vonk, J., and Povinelli, D. J. (2011). Individual differences in long-term cognitive testing in a group of captive chimpanzees. Int. J. Comp. Psychol. 24 137-167.

Warren, D. L., and Iglesias, T. L. (2012). No evidence for the "expensive-tissue hypothesis" from an intraspecific study in a highly variable species. J. Evol. Biol. 25, 1226-1231. doi 10.1111/j.1420-9101.2012.02503.x

Warton, D. I., Wright, I. J., Falster, D. S., and Westoby, M. (2006) Bivariate line-fitting methods for allometry. Biol. Rev. 81, 259-291. doi: $10.1017 /$ S1464793106007007

Washburn, D. A., and Rumbaugh, D. M. (1997). Faster is smarter, so why are we slower? A comparative perspective on intelligence and processing speed. Am. Psychol. 52, 1147-1148. doi: 10.1037/0003-066X.52.10 1147

Weaver, A. H. (2005). Reciprocal evolution of the cerebellum and neocortex in fossil humans. Proc. Natl. Acad. Sci. U.S.A. 102, 3576-3580. doi: 10.1073/pnas.0500692102

Weisbecker, V., and Goswami, A. (2011). Neonatal maturity as the key to understanding brain size evolution in homeothermic vertebrates. Bioessays 33, 155-158. doi: 10.1002/bies.201000128

Weiss, A., Inoue-Murayama, M. King, J. E., Adams, M. J., and Matsuzawa, T. (2012). All too human? Chimpanzee and orang-utan personalities are not anthropomorphic projections. Anim. Behav. 83, 1355-1365. doi: 10.1016/j.anbehav.2012.02.024

Welker, W. I., and Seidenstein, S. (1959). Somatic sensory representation in the cerebral cortex of the racoon (Procyon lotor). J. Comp. Neurol. 111, 469-501. doi: 10.1002/cne.901110306
Whishaw, I. Q. (2003). Did a change in sensory control of skilled movements stimulate the evolution of the primate frontal cortex? Behav. Brain Res. 146, 31-41.

White, C. R., Blackburn, T. M. and Seymour, R. S. (2009). Phylogenetically informed analysis of the allometry of mammalian basal metabolic rate supports neither geometric nor quarter-power scaling. Evolution 63, 2658-2667. doi: 10.1111/j.1558-5646.2009.00747.x

Willemet, R. (2012). Understanding the evolution of mammalian brain structures; the need for a (New) cerebrotype approach Brain Sci. 2, 203-224. doi 10.3390/brainsci2020203

Williams, M. F. (2002). Primate encephalization and intelligence. Med. Hypotheses 58, 284-290. doi 10.1054/mehy.2001.1516

Wilson, M. (2002). Six views of embodied cognition. Psychon. Bull. Rev. 9, 625-636. doi: 10.3758/BF03196322

Winkler, H., Leisler, B., and Bernroider, G. (2004). Ecological constraints on the evolution of avian brains. J. Ornithol. 145 238-244. doi: 10.1007/s10336-004 $-0040-y$

Wolf, M., van Doorn, G. S., Leimar, O., and Weissing, F. J. (2007) Life-history trade-offs favour the evolution of animal personalities. Nature 447, 581-584. doi: $10.1038 /$ nature 05835

Wolf, M., and Weissing, F. J. (2010) An explanatory framework for adaptive personality differences. Philos. Trans. Roy. Soc. B Biol. Sci. 365, 3959-3968. doi: 10.1098/rstb.2010.0215

Woods, V., and Hare, B. (2010). "Think outside the lab: African sanctuaries as a new ressource for non-invasive research on great apes," in Encycopedia of Animal Behavior and Welfare, ed D. Mills (Wallingford: CABI Publishing), 24-25.

Worthy, G. A. J., and Hickie, J. P. (1986) Relative brain size in marine mammals. Am. Nat. 128, 445-459. doi $10.1086 / 284579$

Wright, A. A. (2010). Functional relationships for determining similarities and differences in comparative cognition. Behav. Process. 85, 246-251. doi: 10.1016/j.beproc.2010.07.018

Würbel, H. (2001). Ideal homes? Housing effects on rodent brain and behaviour. Trends Neurosci. 24, 207-211. doi: 10.1016/S0166-2236(00)01718-5

Yaskin, V. A. (1994). "Variation in brain morphology of the common shrew," in Advances in the Biology of Shrews, eds J. F. Merrit, G. Kirkland, and R. K. Rose (Pittsburgh, PA: Carnegie Museum of Natural History Special Publication), 155-161.

Yopak, K. E. (2012). Neuroecology of cartilaginous fishes: the functional implications of brain scaling. J. Fish Biol. 80, 1968-2023. doi: 10.1111/j.1095-8649.2012.03254.x

Yopak, K. E., Lisney, T. J., Darlington, R. B., Collin, S. P., Montgomery, J. C., and Finlay, B. L. (2010). A conserved pattern of brain scaling from sharks to primates. Proc. Natl. Acad. Sci. U.S.A. 107, 12946-12951. doi 10.1073/pnas.1002195107

Young, L. J. (1999). Oxytocin and vasopressin receptors and species-typical social behaviors. Horm. Behav. 36, 212-221. doi 10.1006/hbeh.1999.1548

Conflict of Interest Statement: The author declares that the research was conducted in the absence of any commercial or financial relationships that could be construed as a potential conflict of interest.

Received: 18 April 2013; paper pending published: 13 May 2013; accepted: 12 June 2013; published online: 01 July 2013.

Citation: Willemet $R \quad$ (2013) Reconsidering the evolution of brain, cognition, and behavior in birds and mammals. Front. Psychol. 4:396. doi: 10.3389/fpsyg.2013.00396

This article was submitted to Frontier in Comparative Psychology, a specialty of Frontiers in Psychology.

Copyright (c) 2013 Willemet. This is an open-access article distributed under the terms of the Creative Commons Attribution License, which permits use, distribution and reproduction in other forums, provided the original author and source are credited and subject to any copyright notices concerning any third-party graphics etc. 